\title{
Synaptic Ultrastructure of Functionally and Morphologically Characterized Neurons of the Superficial Spinal Dorsal Horn of Cat
}

\author{
M. Rèthelyi, A. R. Light, and E. R. Perl \\ Department of Physiology, University of North Carolina at Chapel Hill, Chapel Hill, North Carolina 27599, and Second \\ Department of Anatomy, Semmelweis University, Budapest, Hungary
}

Recordings of neuronal unitary discharges evoked by primary afferent input were made in the superficial part of the spinal cord's dorsal horn, the marginal zone and substantia gelatinosa (also known as laminae I and II), using fine micropipette electrodes filled with HRP. After physiological characterization with respect to primary afferent input, HRP was injected intracellularly iontophoretically into the recorded neuron. Following histochemical processing, the neurons so delineated were studied at the light and electron microscopic levels. No clear relationship between function and either general cellular configuration or synaptic ultrastructure appeared in these analyses, although the concentration of dendritic distribution could be related to the nature of primary afferent excitation. Nocireceptive cells had dendrites mostly branching and ending in lamina $I$ and $I_{o}$, while the dendrites of innocuous mechanoreceptive cells arborized principally in lamina II and III. Glomerular synaptic complexes (large, complex arrays of axonic and dendritic profiles with synaptic interconnections) were found to contact a few neurons of both the nocireceptive and mechanoreceptive classes. All neurons received large numbers of simple axonic contacts (small axonic boutons with only 1 or 2 synaptic contacts with a single postsynaptic profile). A degree of specificity in the presynaptic articulations appeared to be reflected by the observations that (1) nocireceptive neurons were never found to receive synaptic contacts from boutons which resembled the known ultrastructure of peripheral innocuous mechanoreceptors, and (2) mechanoreceptive neurons were never seen to receive synaptic contacts from boutons which resembled the known ultrastructure of primary afferent nocireceptors. The axons of the labeled neurons of both nocireceptive and mechanoreceptive classes terminated in simple axonic synapses. All classes of neurons participated in dendrodendritic contacts; however, only some mechanoreceptive neurons had dendrites containing vesicles that were presynaptic to other profiles. No nocireceptive

\footnotetext{
Received Dec. 22, 1987; revised Oct. 10, 1988; accepted Oct. 24, 1988.

We are grateful to Ms. Carol B. Metz for her histological assistance and to Ms. Rozalia Fervagner for expert help with photographic work. Ms. Sherry Derr's bibliographic and editorial assistance in preparation of this manuscript is greatly appreciated. This work was supported by Grant NS10321 from the U.S. National Institute of Neurological Communicative Diseases and Stroke, by a cooperative scientific agreement between the Ministry of Health of Hungary and the United States National Institutes of Health, and by a grant from the IIungarian Academy of Sciences (OKKFT).

Correspondence should be addressed to Dr. E. R. Perl, Department of Physiology, $\mathrm{CB} \# 7545$ MacNider, University of North Carolina-Chapel Hill, Chapel Hill, NC 27599-7545.

Copyright (C) 1989 Society for Neuroscience $0270-6474 / 89 / 061846-18 \$ 02.00 / 0$
}

neurons, regardless of gross configuration, were found to have vesicles in their dendrites, but 3 nocireceptive neurons received synapses from presynaptic dendritic profiles.

The superficial dorsal horn, laminae I and II, of the spinal cord (Brown and Rèthelyi, 1981) receives primary afferent input principally or exclusively from fine fibers, myelinated and unmyelinated, that pass through the lateral division of the dorsal rootlets (Sindou et al., 1974; Snyder, 1977; Light and Perl, 1979a, b). However, from the functional standpoint, the input to the region from the periphery is diverse (Kumazawa and Perl, 1978; Rèthelyi et al., 1979; Perl, 1984). There have been numerous descriptions of the structure of neurons and terminal axon systems located in this part of the spinal gray matter based upon Golgi impregnation techniques by classical and modern neurohistologists (Waldeyer, 1888; Lenhossek, 1895; Golgi, 1903; Ramón y Cajal, 1909; Pearson, 1952; Szentàgothai, 1964; Scheibel and Scheibel, 1968; Matsushita, 1969; Rèthelyi and Szentàgothai, 1973; Sugiura, 1975; Bcal and Fox, 1976; Mannen and Sugiura, 1976; Beal and Cooper, 1978; Beal et al., 1981). While these morphological studies provide a basis for a general understanding of the neuronal configurations in this region, they give no direct evidence concerning relationships between structure and function or on the nature of synaptic articulations.

Light level studies of the neurons in the superficial dorsal horn have generally agreed upon the presence in lamina I of large, flattened neurons with major dendrites arranged to cap the dorsal horn of the type originally described by Waldeyer (1888), along with a substantial number of smaller rostrocaudally oriented cells. It is also generally accepted that lamina II, the substantia gelatinosa, is principally comprised of small densely packed cells; Ramón y Cajal (1909) recognized 2 principal forms: a "limitrophe" type most common at the border with lamina I that shows prominent dendrites radiating deeper into lamina II and a "central" type typically found more deeply in lamina II characterized by an elaborate array of rostrocaudally orientated dendrites with prominent dendritic protrusions. Since the time of Ramón y Cajal on, most observers have recognized 2 such neuronal shapes as characteristic of the substantia gelatinosa, although they have been given different names. Furthermore, most commentators have pointed out that many variations of the 2 basic patterns exist.

Initial views on synaptic organization in the superficial spinal dorsal horn were derived from ultrastructural surveys of normal tissue or following rhizotomy; the latter permitted identification of degenerating terminals of primary afferents fiber (Kerr, 1966, 1970; Ralston, 1968a, b, 1979; Rèthelyi and Szentàgothai, 1969; Coimbra et al., 1974; Knyihar et al., 1974; Narotzky and Kerr, 
1978). These electron microscopic studies have emphasized the presence of "glomerular" synaptic complexes in which a "core axon terminal" was presynaptic to several dendritic profiles and was itself postsynaptic to surrounding profiles. Despite such emphases on the presence of glomerular synaptic complexes, "simple" axonal contacts in which an axonal profile contacts only one dendritic element are the more common articulation of the region (Ralston, 1979). Analysis of a single, functionally identified neuron of lamina II, by Gobel et al. (1980), pointed out that this neuron received a variety of both simple and glomerular synapses.

On circumstantial grounds, either from the relationship of the superficial dorsal horn to the thin fibers in the dorsal roots or to retrograde changes in neurons of the region following ventrolateral chordotomy, an association has been made between the superficial dorsal horn and mechanisms related to pain (Ranson, 1915; Foerster and Gagel, 1932; Kuru, 1949). More recently, electrophysiological observations have provided direct evidence that some neurons of laminae I and II in both carnivore and primate do have nocireceptive characteristics. However, these latter kinds of analyses have also emphasized that other neurons in the same laminae may be excited most effectively by either innocuous tactile or thermal stimuli (Christensen and Perl, 1970; Kumazawa and Perl, 1976, 1978; Dostrovsky and Hellon, 1978; Light et al., 1979). While it is tempting to postulate that each anatomically different cell type has a different functional input, there has been substantial disagreement on this point (Bennett et al., 1979, 1980; Light et al., 1979; Molony et al., 1981).

We report here observations on the structure and ultrastructurc of a group of superficial dorsal horn neurons that were thoroughly characterized with respect to their peripheral input. The results indicate that the light level appearance and synaptic ultrastructure of superficial dorsal horn neurons are only poorly correlated with the type of peripheral input that excites the cell Preliminary reports of some of these findings have been published elsewhere (Rèthelyi et al., 1983, 1985).

\section{Materials and Methods}

Adult cats were deeply anesthetized with a mixture of halothane and nitrous oxide, a tracheal cannula was inserted, and a midcollicular decerebration performed. After the decerebration and destruction of the brain rostral to the colliculi, anesthesia was discontinued. Arterial pressure was monitored from a carotid artery cannula, and a neuromuscular blocking agent (gallamine triethiodide) was administered through a venous cannula. The paralyzed preparation was maintained with positivepressure respiration adjusted to hold end-tidal $\mathrm{CO}_{2}$ to $4 \%$ in air drawn from the tracheal cannula as monitored by an infrared $\mathrm{CO}_{2}$ detector Vertebral clamps and ischial pins were used for rigid support of the spinal region. A laminectomy exposed the spinal cord from the lower lumbar through the coccygeal region. The spinal cord was severed in the lower thoracic region through a separate, small laminectomy. Intact dorsal roots were lifted upon bipolar stimulating and recording electrodes to stimulate and monitor dorsal root afferent volleys.

Recordings were made with fine micropipette electrodes $(<0.1 \mu \mathrm{m}$ $80-200 \mathrm{M} \Omega$ ) filled with 5-10\% HRP (Sigma type VI) in Tris buffer (pH 7.6) and $0.5 \mathrm{M} \mathrm{KCl}$ connected to a high-voltage electrometer with a high-compliance, constant-current source (Jochem et al., 1981). A stepping hydraulic microdrive (Kopf 650) was used to slowly advance the micropipettes into the spinal cord from the dorsal surface. Unitary activity from caudal and sacral segments was recorded initially extracellularly. In most cases these units were first recognized by a response to afferent volleys in the dorsal root fibers; they were characterized by conduction delay, relationship to components of the dorsal root compound action potential, and response to stimulation of peripheral tissue. Peripheral stimulation techniques included stroking of hairs and the skin with soft brushes, pressure applied with von Frey stimulators, blunt pressure against skin or subcutaneous tissue, squeezing of skin with forceps, innocuous warming or cooling, and noxious heat. After initial functional characterization, the recording electrode was manipulated intracellularly, as evidenced by a maintained resting potential, and the responsive characteristics were rechecked. When the intracellular recording was established to be from the same element as studied extracellularly, positive rectangular pulses (ca. $100 \mathrm{~Hz}$ ) of 4-10 nA were applied for $30 \mathrm{sec}-5 \mathrm{~min}$. Attempts to stain neurons were separated by at least $1 \mathrm{~mm}$ along the rostral-caudal direction of the spinal cord

At the end of the electrophysiological recording session, the preparation was perfused with a fixative solution ( $2 \%$ glutaraldehyde, $2.5 \%$ paraformaldehyde in $0.1 \mathrm{~m}$ phosphate buffer with $5 \%$ sucrose) through the carotid cannula. The spinal cord was removed and postfixed in the same solution. The spinal cord was cut by Vibratome in $50-\mu \mathrm{m}$-thick sections in the region of attempted neuronal labeling usually in the parasagittal plane. The tissue sections were reacted with diaminobenzidine and $\mathrm{H}_{2} \mathrm{O}_{2}$ for $1 \mathrm{hr}$ at $4^{\circ} \mathrm{C}$. After washing and wet mounting, sections containing stained neurons were reacted in $\mathrm{OsO}_{4}$ for $1 \mathrm{hr}$ and then embedded in plastic between Teflon-coated coverslips (Metz et al., 1982). Photographs were taken of the sections containing stained neurons. The configurations of stained neurons were drawn using a camera lucida attachment.

Laminar boundaries as described by Rexed (1954) were determined in the osmium-treated, flat-embedded plastic sections. In these sections, lamina III and lamina II are easily distinguished by the large number of longitudinally oriented myelinated axons in lamina III. The superficial limit of lamina I is demarcated by the darkly stained myelinated axons of the dorsal columns. Lamina I contains large multipolar neurons with dendrites that remain primarily within it. The ventral border of lamina I blends into the outer portion of lamina II, and this boundary is difficult to determine. We divided lamina II into inner and outer portions as described by Rexed (1954). Lamina II-outer (abbreviated as $\mathrm{II}_{\mathrm{o}}$ ) contains many longitudinally oriented cell bodies and more myelinated axons than the more internal lamina II-inner (abbreviated II ). Lamina $\mathrm{II}_{\mathrm{i}}$ has relatively few, widely scattered cell bodies and in these osmium-treated sections appears lighter in color than lamina $\mathrm{II}_{\mathrm{o}}$ because of the lack of myelinated axons. The border between these sublaminae was placed just internal to the accumulation of longitudinally oriented cell bodies in $\mathrm{II}_{\text {. }}$.

Selected processes (axons, dendrites, cell bodies) of the stained cells were cut from the plastic wafers, glued to blank Epon blocks, and then cut on an ultramicrotome into ultrathin sections. Many segments of dendrites and axons were examined in serial sections covering extensive stretches of the structure of interest. For each labeled neuron several thousand ultrathin sections ( $\sim 70-100 \mathrm{~nm}$ thick) were cut from the 50$\mu \mathrm{m}$-thick plastic embedded wafers. The ultrathin sections were cut from regions selectively chosen with the aid of detailed drawings of the labeled dendrites and axon collaterals so as to sample particular structures. The ultrathin sections were treated with lead citrate and uranyl acetate for contrast. After careful observations of the ultrastructure from the large group of sections, 60-200 serial ultrathin sections from each neuron containing synaptic specializations were photographed and used as the basis for the observations in Tables 1-3. In each ultrathin section, several portions of the dendritic tree were usually recovered.

The description of the ultrastructure of the labeled axon enlargements originating from HRP-stained neurons was based on 32 boutons obtained from 7 neurons (Table 3: B,D,A,L,N,O,P). A complete series of sections was analyzed for 15 boutons. Electron micrographs of representative structures were taken at various powers.

Note: In the material presented, comments about particular neurons are identified by letters $A-R$, referring to cells so labeled in Figure 1 and Tables 1-3. In the electron micrographs the upper case letters $A-$ $R$ also indicate the neurons of Table $1-3$ from which the material was taken.

\section{Results}

In unanesthetized, decerebrated, and spinalized preparations with good vital signs, only a small fraction of neuronal units in the superficial dorsal horn that are excited by primary afferent input exhibit significant background activity (over 1 impulse/5 sec). On the other hand, injury by the recording microelectrode as evidenced by very large action potentials accompanied by varying baseline negativity was often associated with the ap- 


\section{Table 1. Selectively nocireceptive neurons}

\begin{tabular}{|c|c|c|c|c|c|c|}
\hline Code & $\begin{array}{l}\text { Size of } \\
\text { the peri- } \\
\text { karyon } \\
(\mu \mathrm{m})\end{array}$ & $\begin{array}{l}\text { Mechanism of the } \\
\text { excitation }\end{array}$ & $\begin{array}{l}\text { Cell type, distribution } \\
\text { of the dendrites }\end{array}$ & $\begin{array}{l}\text { Syn- } \\
\text { apses } \\
\text { on } \\
\text { soma }\end{array}$ & Synapses on dendrites & $\begin{array}{l}\text { Local axon } \\
\text { arborization }\end{array}$ \\
\hline A & $18 \times 22$ & $\begin{array}{l}\text { Myelinated mechanical } \\
\text { nocireceptive }\end{array}$ & $\begin{array}{l}\text { Central cell, dendrites in } \mathrm{I} \text { and } \mathrm{II}_{\mathrm{o}} \\
\text { numerous protrusions }\end{array}$ & Yes & $\begin{array}{l}\text { Simple synapses, axon terminals } \\
\text { with large dense-core vesicles }\end{array}$ & $\begin{array}{l}\text { Myelinated axon, } \\
\text { no local } \\
\text { collaterals }\end{array}$ \\
\hline B & $12 \times 19$ & $\begin{array}{l}\text { Myelinated mechanical } \\
\text { nocireceptive }\end{array}$ & $\begin{array}{l}\text { Central-limitroph combination, } \\
\text { dendrites in I-II, numerous } \\
\text { protrusions }\end{array}$ & n.a. & $\begin{array}{l}\text { Simple synapses, } \\
\text { dendrodendritic synapses onto } \\
\text { dendrites }\end{array}$ & $\begin{array}{l}\text { Rich } \\
\text { arborization in } \\
\text { I-III }\end{array}$ \\
\hline C & $18 \times 20$ & $\begin{array}{l}\text { Myelinated mechanical } \\
\text { and weak } \\
\text { thcrmonocircceptivc }\end{array}$ & $\begin{array}{l}\text { Central cell, dendrites in } \mathrm{I} \text { and } \mathrm{II}_{\mathrm{o}} \text {, } \\
\text { numerous protrusions }\end{array}$ & No & $\begin{array}{l}\text { Glomerular HTM-type, simple } \\
\text { and dendrodenritic synapses } \\
\text { onto dendrites }\end{array}$ & $\begin{array}{l}\text { Rich } \\
\text { arborization in } \\
\text { I-II }\end{array}$ \\
\hline $\mathrm{D}$ & $20 \times 25$ & $\begin{array}{l}\text { Myelinated mechanical } \\
\text { and weak } \\
\text { thermonocireceptive }\end{array}$ & $\begin{array}{l}\text { Central cell, dendrites in } \mathrm{I} \text { and } \mathrm{II}_{\mathrm{o}} \\
\text { numerous protrusions }\end{array}$ & No & $\begin{array}{l}\text { Glomerular HTM-type and } \\
\text { simple synapses }\end{array}$ & $\begin{array}{l}\text { Rich } \\
\text { arborization in } \\
\text { I-II }\end{array}$ \\
\hline $\mathrm{E}$ & $15 \times 18$ & $\begin{array}{l}\text { Myelinated mechanical } \\
\text { and weak } \\
\text { thermonocireceptive }\end{array}$ & $\begin{array}{l}\text { Central cell, dendrites in } \mathrm{I} \text { and } \mathrm{II}_{\mathrm{o}} \text {, } \\
\text { numerous protrusions }\end{array}$ & No & $\begin{array}{l}\text { Simple synapses, axon terminals } \\
\text { with large dense-core vesicles }\end{array}$ & $\begin{array}{l}\text { Rich } \\
\text { arborization in } \\
\text { I-II }\end{array}$ \\
\hline $\mathrm{F}$ & $20 \times 25$ & $\begin{array}{l}\text { Myelinated and } \\
\text { unmyelinated } \\
\text { mechanical } \\
\text { nocireceptive }\end{array}$ & Limitroph cell, numerous protrusions & No & Simple synapses & Arborization in I \\
\hline G & $12 \times 24$ & $\begin{array}{l}\text { Myelinated and } \\
\text { unmyelinated } \\
\text { mechanical } \\
\text { and weak } \\
\text { thermonocireceptive }\end{array}$ & Limitroph cell, smooth dendrites & Yes & Simple synapses & Not stained \\
\hline $\mathbf{H}$ & $24 \times 28$ & $\begin{array}{l}\text { Myelinated and } \\
\text { unmyelinated } \\
\text { mechanical } \\
\text { nocireceptive }\end{array}$ & Limitroph cell, numerous protrusions & n.a. & $\begin{array}{l}\text { Simple synapse and occasional } \\
\text { glomerular endings in IIi }\end{array}$ & $\begin{array}{l}\text { Few collaterals } \\
\text { in I and II }\end{array}$ \\
\hline I & n.a. & $\begin{array}{l}\text { Myelinated mechanical } \\
\text { and weak } \\
\text { thermonocireceptive }\end{array}$ & $\begin{array}{l}\text { Limitroph cell, numerous protrusions } \\
\text { (cut in the transverse plane) }\end{array}$ & n.a. & $\begin{array}{l}\text { Simple synapses and } \\
\text { dendrodendritic synapses onto } \\
\text { dendrites }\end{array}$ & Not stained \\
\hline
\end{tabular}

n.a., not available.

pearance of background discharge. Units excited by innocuous thermal stimuli and some multireceptive elements were exceptions in that background discharge was present in the absence of any indication of injury. Inhibition from peripheral stimulation could be demonstrated for all units. The usual absence of background activity, however, demanded the evocation of responses by nerve volleys or some form of adequate stimuli to test for inhibition; therefore, in practice it proved difficult to systematically analyze inhibitory patterns. For this reason, the nature of the effective excitatory input became the principal basis for classification of functional responses. Using criteria derived from previous studies (Christensen and Perl, 1970; Kumazawa and Perl, 1978; Light et al., 1979), the neuronal units studied were placed into 4 general functional categories.

Most of the units encountered in the superficial dorsal horn using our very fine micropipette electrodes were selectively excited by a limited spectrum of stimuli, commonly either noxious or innocuous mechanical stimulation. Receptive fields were on the tail, the perianal region, or upper thigh. They varied in size from about $1 \mathrm{~cm}^{2}$ to over $5 \mathrm{~cm}^{2}$ with well-defined borders. The selectively nocireceptive or selectively mechanoreceptive categories included some neurons receiving essentially all excitatory drive from sense organs with myelinated peripheral fibers (evidencing no C-fiber-related excitation in extra- or intracellular recording) and others receiving excitatory inputs (as evidenced by action potentials or intracellularly recorded EPSPs) associated with activity in both myelinated and unmyelinated peripheral fibers. Neuronal units classified as selectively mechanoreceptive were effectively excited by innocuous mechanical stimulation and exhibited no greater or special response to noxious stimuli. Elements classified as selectively nocireceptive were either not or weakly (an occasional impulse) excited by any form of innocuous mechanical or innocuous thermal stimulation; they were consistently and maximally activated by injurious mechanical and/or harmful thermal stimulation of peripheral tissue. Neurons classified as selectively thermal units were either strongly excited by an innocuous cutaneous cooling or (less frequently) warming and were poorly activated (few or inconsistent impulses) or unresponsive to any intensity of mechanical stimulation. Selectively thermal units were encountered infrequently, and none that were stained were preserved suitably for ultrastructural analysis. Multireceptive elements ("wide dynamic range"), those effectively excited by innocuous stimuli but responding with a higher frequency or more prolonged discharge 


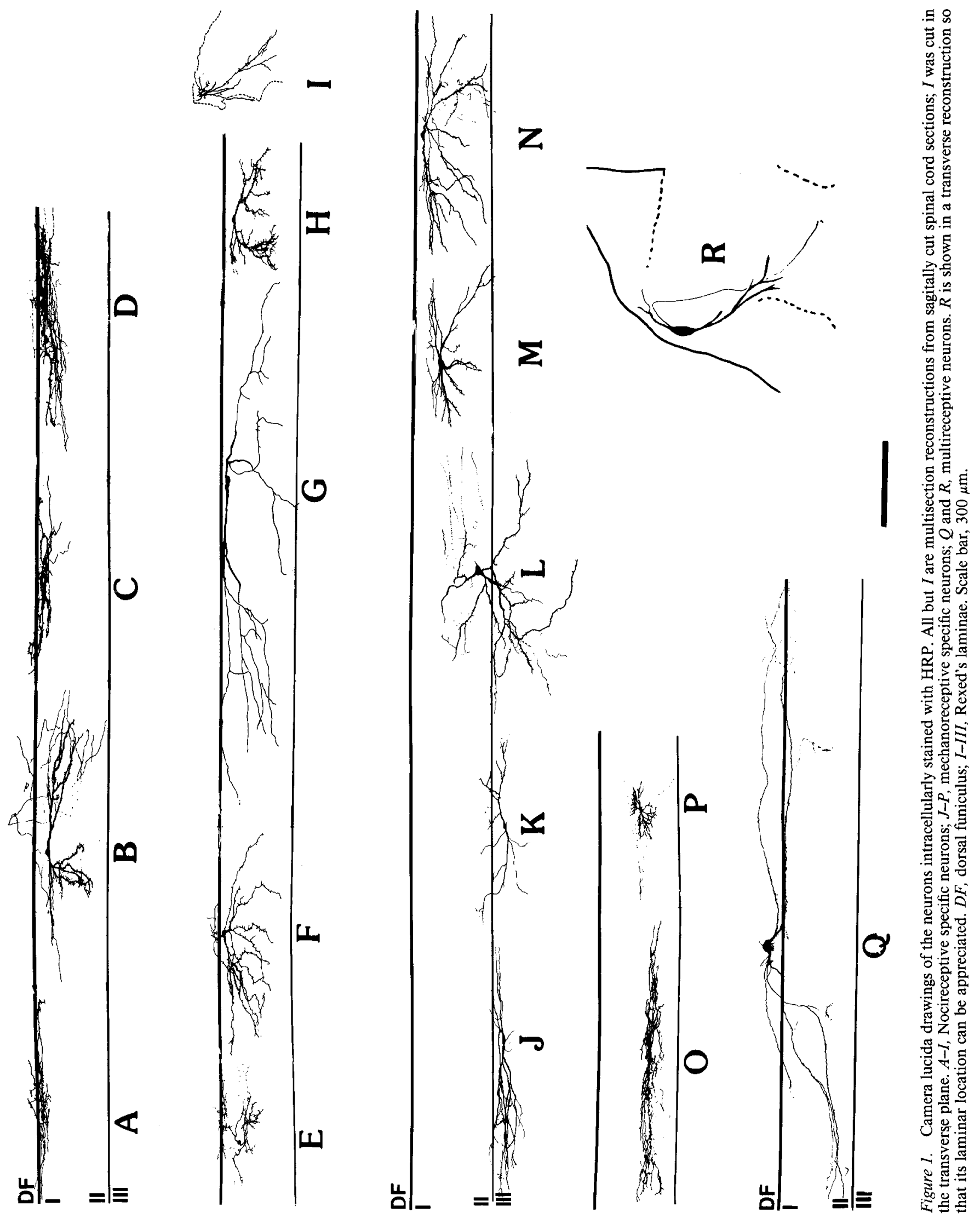


Table 2. Selectively mechanoreceptive and multireceptive neurons

\begin{tabular}{|c|c|c|c|c|c|c|}
\hline Code & $\begin{array}{l}\text { Size of } \\
\text { the peri- } \\
\text { karyon } \\
(\mu \mathrm{m})\end{array}$ & $\begin{array}{l}\text { Mechanisms of the } \\
\text { excitation }\end{array}$ & $\begin{array}{l}\text { Cell type, distribution } \\
\text { of the dendrites }\end{array}$ & $\begin{array}{l}\text { Syn- } \\
\text { apses } \\
\text { on } \\
\text { soma }\end{array}$ & Synapses on dendrites & $\begin{array}{l}\text { Local axon } \\
\text { arborization }\end{array}$ \\
\hline $\mathrm{J}$ & $10 \times 34$ & $\begin{array}{l}\text { Myelinated innocuous } \\
\text { mechanoreceptive } \\
\text { (hair afferents) }\end{array}$ & $\begin{array}{l}\text { Central cell, at the junction of II and III, } \\
\text { few protrusions }\end{array}$ & n.a. & $\begin{array}{l}\text { Large glomerular synapses, } \\
\text { synaptic vesicle containing } \\
\text { dendrites that contact other } \\
\text { neurons. }\end{array}$ & Not stained \\
\hline $\mathrm{K}$ & $10 \times 18$ & $\begin{array}{l}\text { Myelinated innocuous } \\
\text { mechanoreceptive } \\
\text { (hair afferents) }\end{array}$ & $\begin{array}{l}\text { Central cell, at the junction of II and III, } \\
\text { few protrusions }\end{array}$ & Yes & $\begin{array}{l}\text { Large glomerular and simple } \\
\text { synapses }\end{array}$ & Not stained \\
\hline $\mathrm{L}$ & $13 \times 18$ & $\begin{array}{l}\text { Myelinated innocuous } \\
\text { mechanoreceptive } \\
\text { (slow brush type) }\end{array}$ & $\begin{array}{l}\text { Central (circular) cell, dendrites in IIi } \\
\text { and III, few protrusions }\end{array}$ & No & Simple synapses & $\begin{array}{l}\text { Axon } \\
\text { arborization in } \\
\text { II }\end{array}$ \\
\hline M & $18 \times 22$ & $\begin{array}{l}\text { Myelinated innocuous } \\
\text { mechanoreceptive } \\
\text { (slow brush type) }\end{array}$ & Limitroph cell, few protrusions & Yes & $\begin{array}{l}\text { Large glomerular type and } \\
\text { simple synapses }\end{array}$ & Not stained \\
\hline $\mathrm{N}$ & $20 \times 28$ & $\begin{array}{l}\text { Myelinated innocuous } \\
\text { mechanoreceptive } \\
\text { (slow brush type) }\end{array}$ & Limitroph cell, few protrusions & n.a. & Simple synapses & $\begin{array}{l}\text { Axon } \\
\text { arborization in } \\
\text { I and II, } \\
\text { partially } \\
\text { myelinated } \\
\text { axon }\end{array}$ \\
\hline $\mathrm{O}$ & $22 \times 25$ & $\begin{array}{l}\text { Myelinated and } \\
\text { unmyelinated } \\
\text { innocuous } \\
\text { mechanoreceptive } \\
\text { (slow brush type) }\end{array}$ & $\begin{array}{l}\text { Lamina II central cell, numerous } \\
\text { protrusions }\end{array}$ & No & $\begin{array}{l}\text { Large glomerular synapses, } \\
\text { synaptic vesicle containing } \\
\text { dendrites that contact other } \\
\text { neurons }\end{array}$ & $\begin{array}{l}\text { Extensive } \\
\text { arborization in } \\
\text { I-III }\end{array}$ \\
\hline$P$ & $12 \times 20$ & $\begin{array}{l}\text { Myelinated and } \\
\text { unmyelinated } \\
\text { innocuous } \\
\text { mechanoreceptive } \\
\text { (slow brush type) }\end{array}$ & Central (circular) cell, dendrites in II & No & Simple synapses & $\begin{array}{l}\text { Extensive } \\
\text { arborization in } \\
\text { I-III }\end{array}$ \\
\hline Q & $23 \times 42$ & $\begin{array}{l}\text { Myelinated and } \\
\text { unmyelinated } \\
\text { (multireceptive) }\end{array}$ & $\begin{array}{l}\text { Waldeyer-type neuron in I numerous } \\
\text { protrusions on the soma and on } \\
\text { dendrites }\end{array}$ & Yes & $\begin{array}{l}\text { Simple synapses with large } \\
\text { dense-core vesicles }\end{array}$ & Not stained \\
\hline $\mathbf{R}$ & $38 \times 57$ & $\begin{array}{l}\text { Myelinated and } \\
\text { unmyelinated } \\
\text { (multireceptive) }\end{array}$ & $\begin{array}{l}\text { Waldeyer-type neuron in I smooth } \\
\text { dendrites }\end{array}$ & Yes & Simple synapses & $\begin{array}{l}\text { Myelinated axon, } \\
\text { collaterals to I } \\
\text { and deeper } \\
\text { areas }\end{array}$ \\
\hline
\end{tabular}

n.a., not available.

to overtly noxious stimulation, were almost as rare as the selectively thermal units in the superficial dorsal horn. Most of the multireceptive units were axonal recordings, as contrasted with the other types that clearly exhibited the synaptic potentials characteristic of soma-dendritic regions. Multireceptive cells were usually large neurons located in the outermost part of the dorsal horn [lamina I, Fig. $1(Q, R)$ or the adjacent white matter].

Eighteen neurons whose somata and dendritic arborizations were well stained by HRP were selected for detailed light and electron microscopic study. These included 9 selectively nocireceptive, 7 selectively mechanoreceptive (low threshold), and 2 multireceptive neurons.

Even though the selection of units to be studied morphologically was based on the suitability of the staining and tissue preservation for microscopic study, those chosen represented a fair sample of elements encountered under these experimental conditions as judged by the functional type, cell location, and general cell configuration. The breakdown of the population of other units in this study and in other series of recordings from this laboratory generally conformed to the present subset. Characteristics of the neurons in the study are presented in Tables 1 and 2, including details of afferent excitation, cell soma location, and general cell configuration (using terminology from the literature of the most closely corresponding neuronal type). The tables also describe briefly the types of contacts found upon the cell and the nature of the local collaterals of the axon whenever the latter could be determined.

\section{Cell location and configuration}

The neurons in the sample were located in the region bounded superficially by the white matter just outside lamina I (marginal zone) and deeply by the superficial portions of lamina III. There was only a loose correlation between the location of neuronal soma and the functional category of the cell. As is shown in 


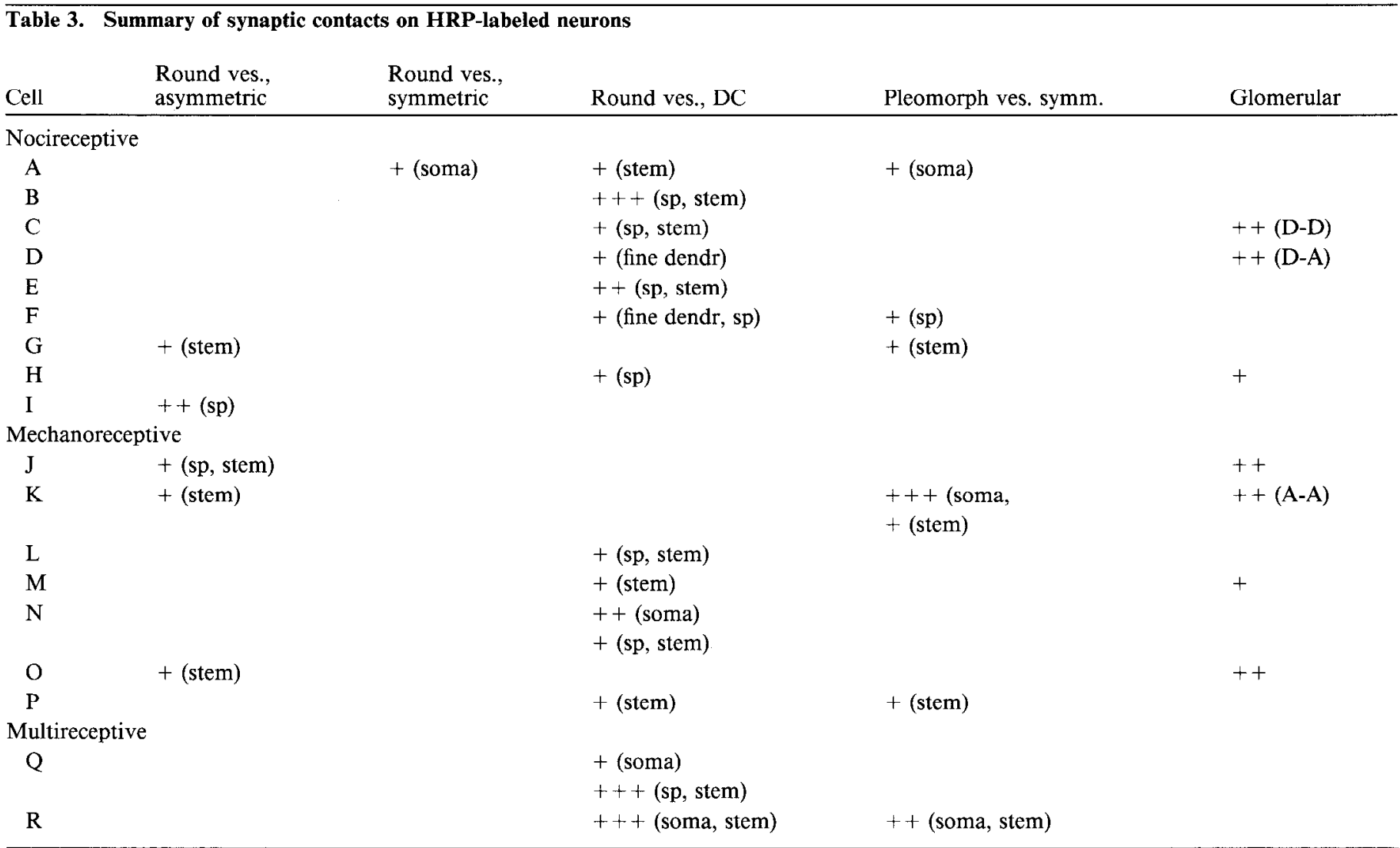

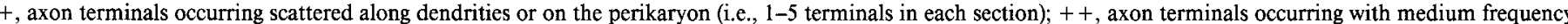

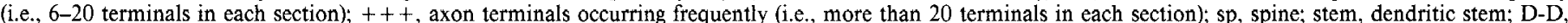

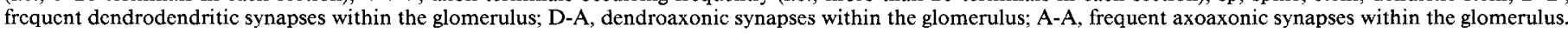

Figure $1(A-I)$, selectively nocireceptive neurons had their somas in lamina $\mathrm{I}$ or in the outer portion of lamina $\mathrm{II}\left(\mathrm{II}_{\mathrm{o}}\right)$. On the other hand, low-threshold mechanoreceptive neurons (Fig. 1, $J-P$ ) had somas scattered from lamina I through the outer portion of lamina III. One of the 2 multireceptive neurons (Fig. $1 Q$ ) had its cell body in the dorsal funiculus, while the other (Fig. 1R) had a soma on the lateral edge of lamina I.

\section{Dendritic distribution}

A better correlation appeared between the principal orientation and distribution of dendrites of a neuron and the dominant excitatory input. Nocireceptive neurons had their major dendritic arborizations in laminae $\mathrm{I}$ and $\mathrm{II}_{\mathrm{o}}$. Nocireceptive cells evidencing excitation only related to primary afferent A-fibers had dendritic arborizations principally in lamina I (Fig. 1, $A-$ $E$ ), although some neurons had more deeply penetrating dendritic extensions as well. Those nocireceptive neurons for which both an A- and a C-fiber excitatory input could be demonstrated had their principal dendritic arborizations spread between laminae I and III (Fig. 1, F-I). As Table 1 and Figure 1 point out, nocireceptive cells included both limitrophe (neurons $B, F-I$ ) and central (neurons $A, C-E$ ). The major dendritic arborizations for the innocuous mechanoreceptive cells were largely arranged within inner lamina II (IIi) and the outer part of lamina III (Fig. $1, J-P)$. Innocuous mechanoreceptive neurons also included both limitrophe (neurons $M$ and $N$ ) and central types (neurons $J, K$, and $O$ ). The 2 stained neurons of the sample with distinctive multireceptive characteristics proved to be large, Waldeyer-type neurons, both of whose dendrites were largely located in lamina I (Fig. 1, $Q, R$ ), and one of which (Fig. 1R) had its dendrites wrapped around the lateral edge of the dorsal horn to enter the gray matter below the nucleus proprius in lamina $\mathrm{V}$.

\section{Axons}

The fine axons of labeled nocireceptive and mechanoreceptive neurons were found to originate either from the soma or proximal dendrites. Some of these could be followed to terminal arborizations where they distributed small en passant boutons, while other axon branches passed into the dorsal or lateral white matter, where they faded and were lost. The axons of 2 neurons (Fig. $1 A$, a central type, and Fig. $1 N$, a limitrophe type) became invested with a thin myelin sheath close to the initial segment. The axons of both multireceptive neurons (Fig. 1, $Q, R$ ) were much thicker than any of the others in the sample. That of Fig. $1 R$ measured $3.1 \mu \mathrm{m}$ in diameter; after traversing lamina I for about $110 \mu \mathrm{m}$, it became invested with a thick myelin sheath and issued thin unmyelinated collaterals that ended within lamina I and more deeply.

\section{Ultrastructural observations}

The labeled neurons were contacted by a variety of axon terminals mainly along their dendrites and on dendritic spines when such spines were present. Only a few perikarya had synapses. Synapsing axon terminals could be grouped into 2 general classes: simple and complex. Table 3 indicates the relative frequency of the various types of contacts on each of the neurons in the present sample. 
Figure 2. Electron micrographs showing simple synaptic contacts between axon terminals $(t)$ containing round or slightly oval clear synaptic vesicles and labelled neurons (asterisks), arrows point to the synaptic specializations. The upper case letter in each panel's upperright corner indicates the code of the neuron (see Fig. 1 and Tables 1 and 2). $a$, Two terminals synapse with labeled spine heads; $b$, a terminal synapses on a dendritic shaft; $c$, the postsynaptic element is a protrusion, double arrows point to the presynaptic axon; $d$, the terminal synapses on a smooth dendrite, among the 2 other terminals $t_{1}$ synapses with the labeled dendrite at some distance from this level, $t_{2}$ proceeds without any synaptic contact. Scale bar, $1 \mu \mathrm{m}$.
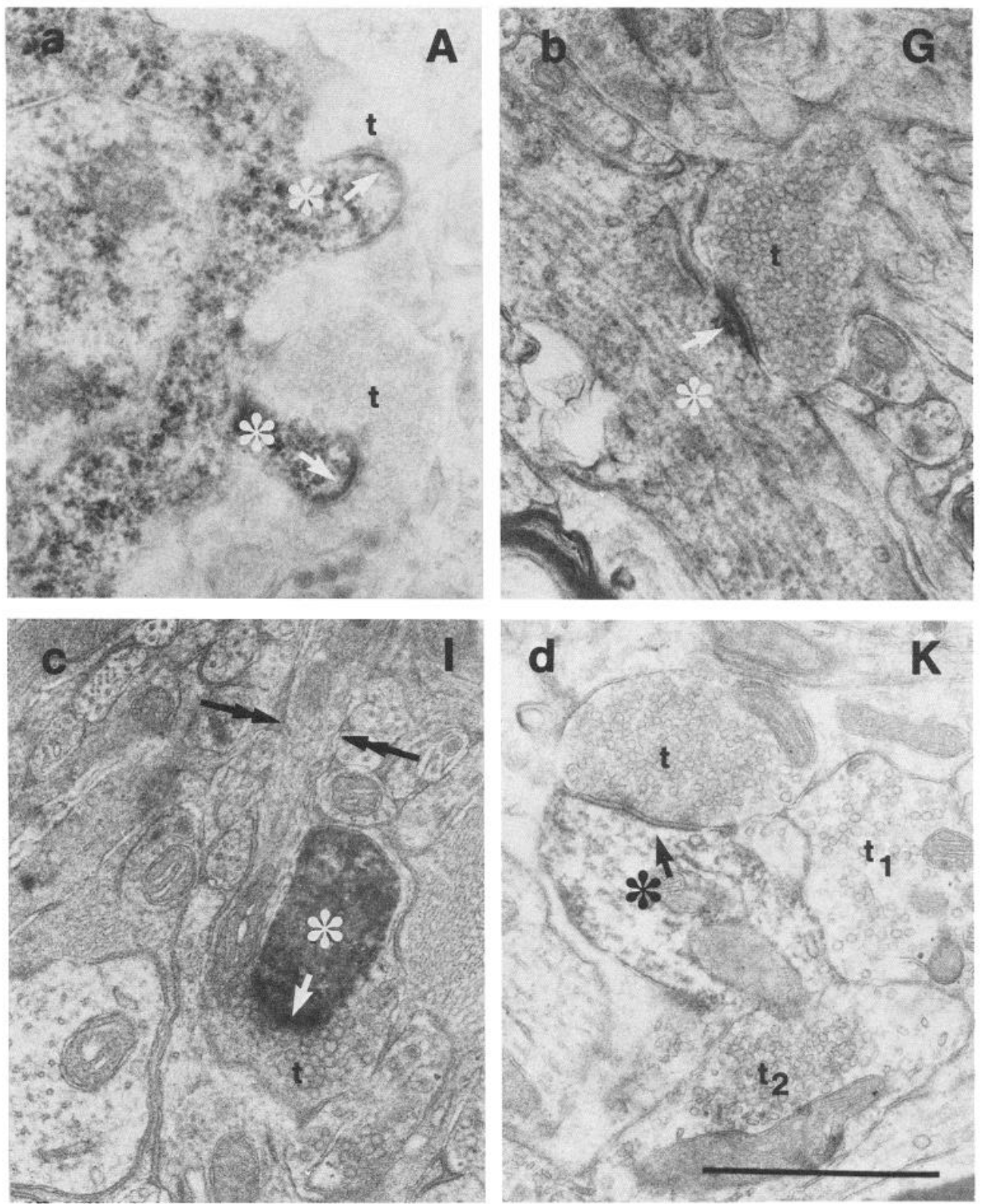

\section{Simple synapses}

The most common type of simple synapse on labeled neurons came from profiles that contained round or slightly oval clear vesicles $40-60 \mathrm{~nm}$ in diameter and in addition contained 1 or more large, dense-core vesicles $80-120 \mathrm{~nm}$ in diameter (LGV type; Ralston, 1979). The synaptic specializations formed by these contacts were asymmetric with the most prominent density in the postsynaptic element. All of the nocireceptive neurons received contacts of this kind on their spines and dendrites with especially frequent contacts of this type being found on $B$ and $E$ (see Table 3). These types of contacts were most numerous in laminae $\mathrm{I}$ and $\mathrm{II}_{\mathrm{o}}$. Examples are shown in Figure 3, a-d. Contacts of the LGV type were also found on 5 of the 7 innocuous mechanoreceptive neurons and were very common on both of the multireceptive neurons.

A less commonly observed simple synapse had a presynaptic axon terminal that contained only round, or slightly oval, clear vesicles $40-60 \mathrm{~nm}$ in diameter (Ralston's $R$ type). The synaptic specialization was asymmetric. The $\mathrm{R}$ type of contact was found on 2 of the nocireceptive neurons $(G$ and $I)$ and on 3 of the innocuous mechanoreceptive neurons $(J, K, O)$. Examples are shown in Figure $2, a-d$. One neuron $(A)$ received a symmetric synapse on its cell soma from simple axonic terminals with only clear, round vesicles. Whether this soma synapse represents a different type of contact or whether it reflects simply a difference between soma and dendritic innervation is not clear. It is reported that somatic contacts rarely exhibit the prominent postsynaptic densities associated with dendritic contacts (Conradi et al., 1979; H. J. Ralston, personal communication).

A third type of simple synaptic contact was frequent on all classes of neurons in this sample. The presynaptic axon terminal in this latter type contained flattened or pleomorphic, clear vesicles and the junction displayed a symmetric specialization. These, thus, represent Ralston's (1979) F-type. F-types of contact usually appeared as single profiles (Fig. $4, a-c$ ) or inter- 

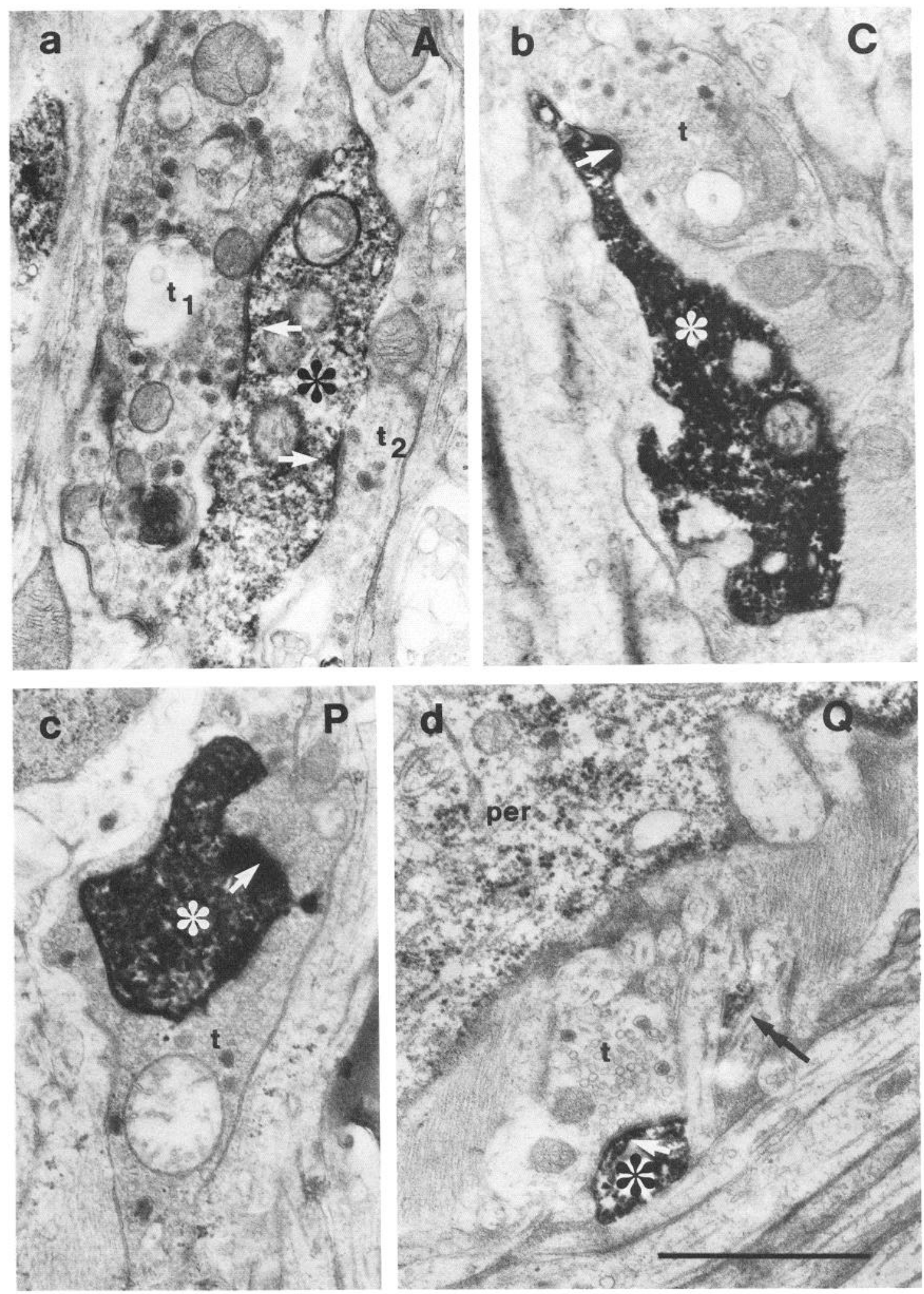

Figure 3. Electron micrographs showing simple synaptic contacts between axon terminals $\left(t, t_{1}\right.$, and $\left.t_{2}\right)$ containing clear and dense-core vesicles and labeled neurons (asterisks), arrows point to the synaptic specializations. The upper case letter in each panel's upper-right corner indicates the code of the neuron (see Fig. 1 and Tables 1 and 2). $a$, The dendrite is surrounded by axon terminals; $b$ and $c$, the terminals are synapsing on dendritic shafts; $d$, the terminal synapses with the head of a somatic protrusion, the labeled perikaryon (per) can be seen in the upper-left corner of the picture, double arrow points to the neck of the protrusion. Scale bar, $1 \mu \mathrm{m}$. 

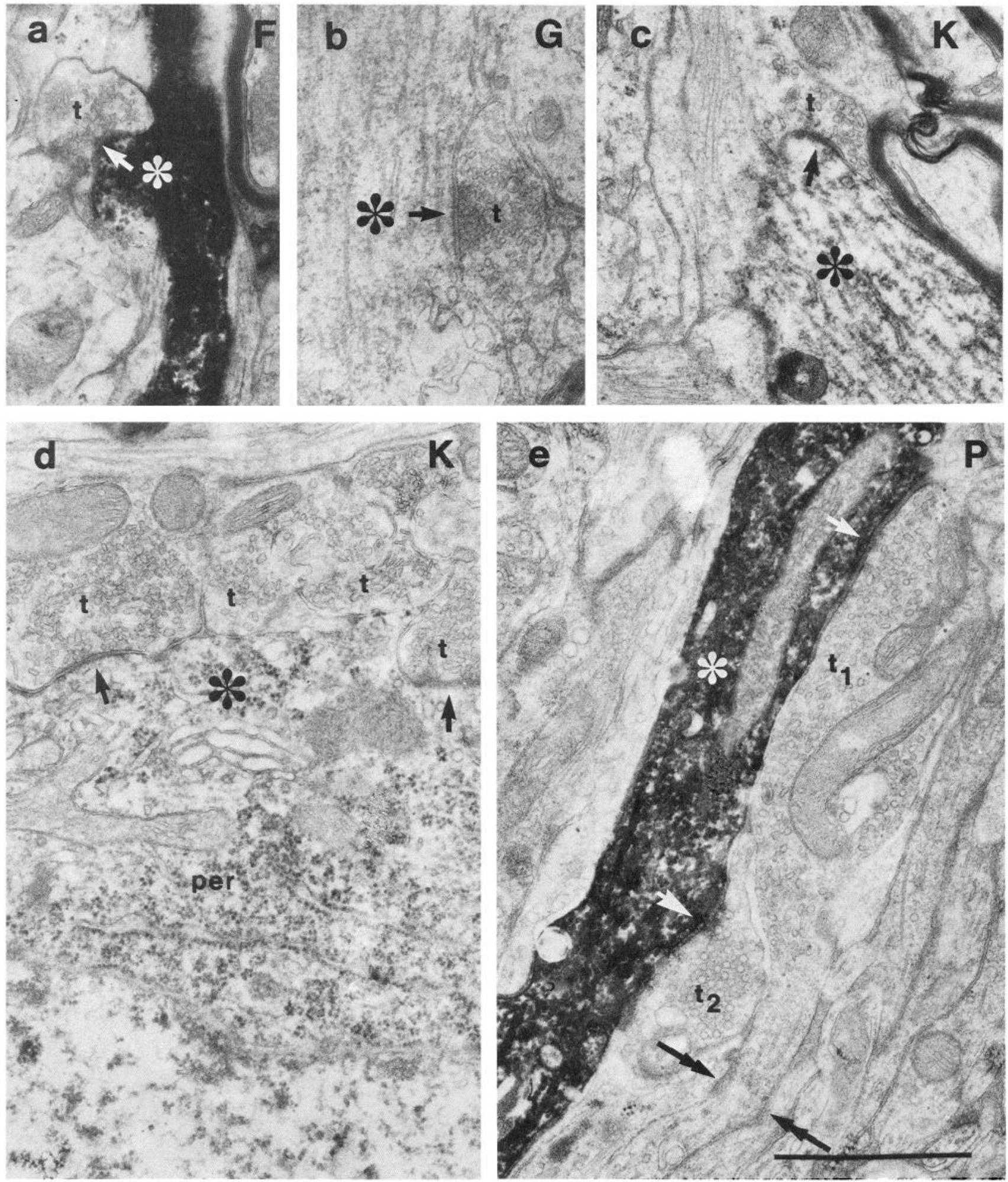

Figure 4. Electron micrographs showing simple synaptic contacts between axon terminals $(t)$ containing flattened synaptic vesicles and labeled neurons (asterisks), arrows point to the synaptic specializations. The upper case letter in each panel's upper-right corner indicates the code of the neuron (see Fig. 1 and Table 1 and 2). $a$, A small terminal caps a short dendritic spine; $b$ and $c$, small terminals synapse on dendritic shafts; $d$, terminals completely cover the surface of a perikaryon (per); $e, 2$ terminals $\left(t_{1}\right.$ containing flattened vesicles, $t_{2}$ containing spherical vesicles) synapse side by side, double arrows point to the stem axon of $t_{1}$. Scale bar, $1 \mu \mathrm{m}$.

mingled with R or LGV boutons (Fig. 4e). However, in some cases several F-type boutons covered large areas of the perikarya (Fig. 4d).

The distribution of simple axodendritic contacts on different neurons varied distinctly. Contacts from axons were scattered along the dendritic surface on most neurons, leaving stretches of 1-5 $\mu \mathrm{m}$ without synapses; a number of examples appear in Figures $2 b, 3 b$, and $4, a, e$. In contrast, in other cases, axonic 

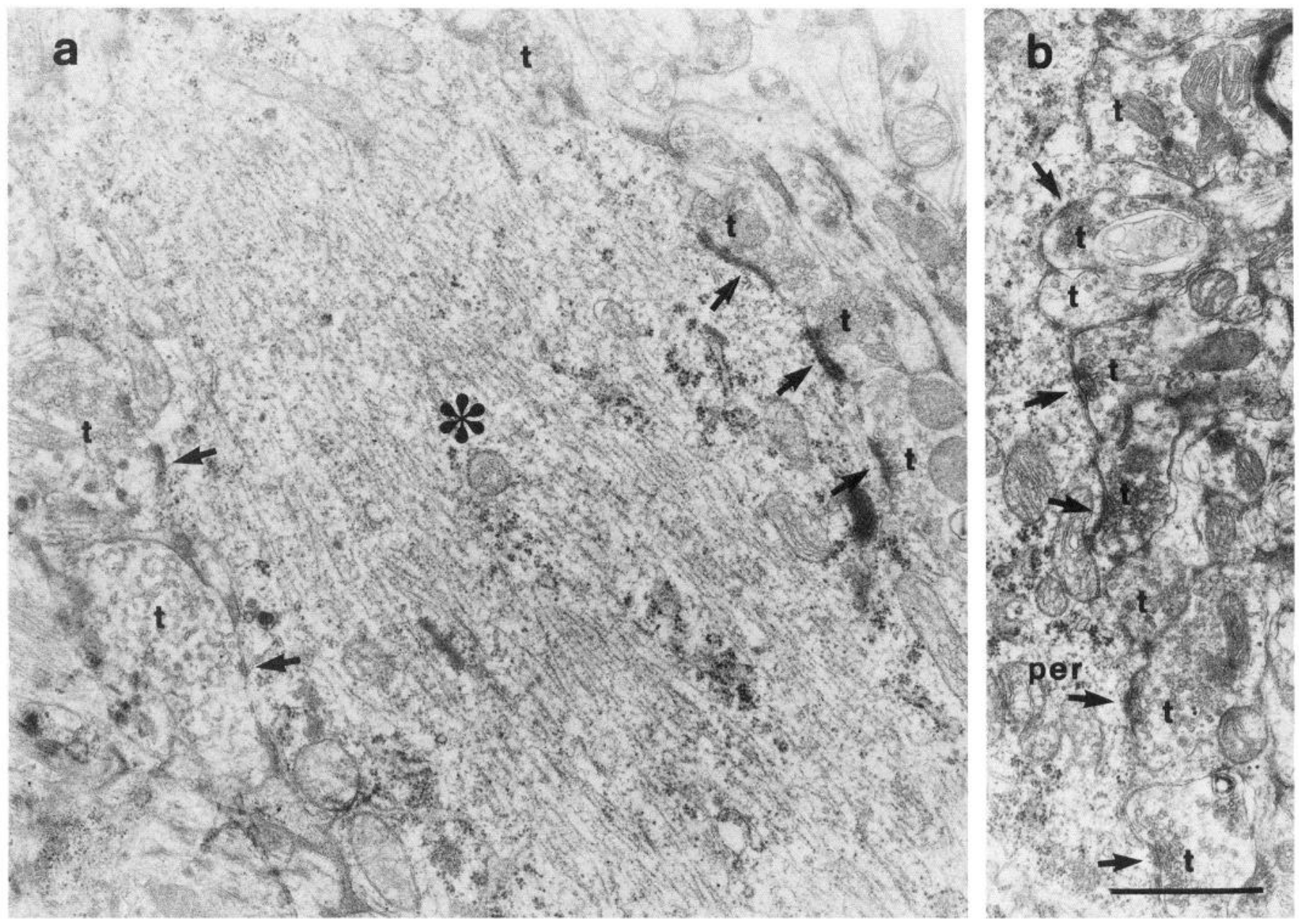

Figure 5. Electron micrographs showing a main dendritic shaft $\left(a,{ }^{*}\right)$ and a portion of the perikaryon $(b$, per) of a multireceptive neuron (neuron $\mathrm{R}$ in Fig. 1 and Table 2). The postsynaptic surfaces on both structures are densely covered by synapsing axon terminals ( $t$ ), arrows point to the synaptic specializations. Scale bar, $1 \mu \mathrm{m}$.

junctions were situated close to one another essentially covering the dendritic or perikaryal surface (e.g., Fig. 5, $a, b$ ). One selectively nocireceptive neuron (Fig. $1 b$ ) showed an unusual arrangement in that its major dendritic shafts passing ventrally in lamina II $_{i}$ were surrounded by many fine unmyelinated fibers (Fig. 6a); one or another of these fine fibers periodically exhibited varicose enlargements that either formed simple synapses with the labeled shaft (Fig. $6 b$ ) or with narrow protrusions from the shaft (Fig. 6c).

\section{Complex synapses}

Complex synaptic contacts consisted of arrangements (glomeruli) in which a large central bouton synapses with several surrounding dendrites and dendritic spines (Kerr, 1966; Rèthelyi and Szentàgothai, 1969). One or more of the contacted dendritic profiles were processes of the HRP-labeled neuron. The profiles forming the center of the glomerular complexes contained clear, round synaptic vesicles $40-80 \mathrm{~nm}$ in diameter. Besides being the presynaptic element to multiple structures, the central profile itself often received contacts from small, vesicle-containing enlargements exhibiting both axonic and dendritic characteristics. Examples of complex synapses taken from serial sections from which the relationships of each pre- and postsynaptic profile could be established are shown in Figure 7, $a, b$. For example, the profiles in Figure $7 b$ marked $a f_{1}$ and $a f_{2}$ (small size axon profiles) on other sections were found in serial reconstruction to be presynaptic to the centrally located axon. Column 6 of Tables 1 and 2 indicates that 7 of the 18 neurons participated in glomerular synapses.

Two of the 9 nocireceptive neurons $(C$ and $D$, both islet cell type) were contacted along their dendritic shafts or spines in laminae I and II by complex glomerular synapses (see example in Fig. 7a). The central bouton of these glomeruli resembled boutons from myelinated nocireceptors in that they were small, contained mostly clear, round vesicles with essentially no large, dense-core vesicles and they contacted only a few (3-5) postsynaptic elements (Rèthelyi et al., 1982). A different nocireceptive neuron, a limitrophe type $(H)$, received complex synapses on dendritic spines in lamina II. The central boutons in the glomeruli synapsing upon this latter neuron were of the C-type; $\mathrm{C}$ boutons are characterized by a large size, contacting a large number of postsynaptic elements and the presence of both large, dense-core vesicles as well as numerous clear, round vesicles.

Two innocuous mechanoreceptive neurons $(J$ and $M)$ also participated in glomeruli in lamina II; the central bouton in both cases was of the C-type. Two other low-threshold mechanoreceptive cells $(K$ and $O$ ) were part of glomeruli at the lamina II-III border, glomeruli that had large single central boutons of 

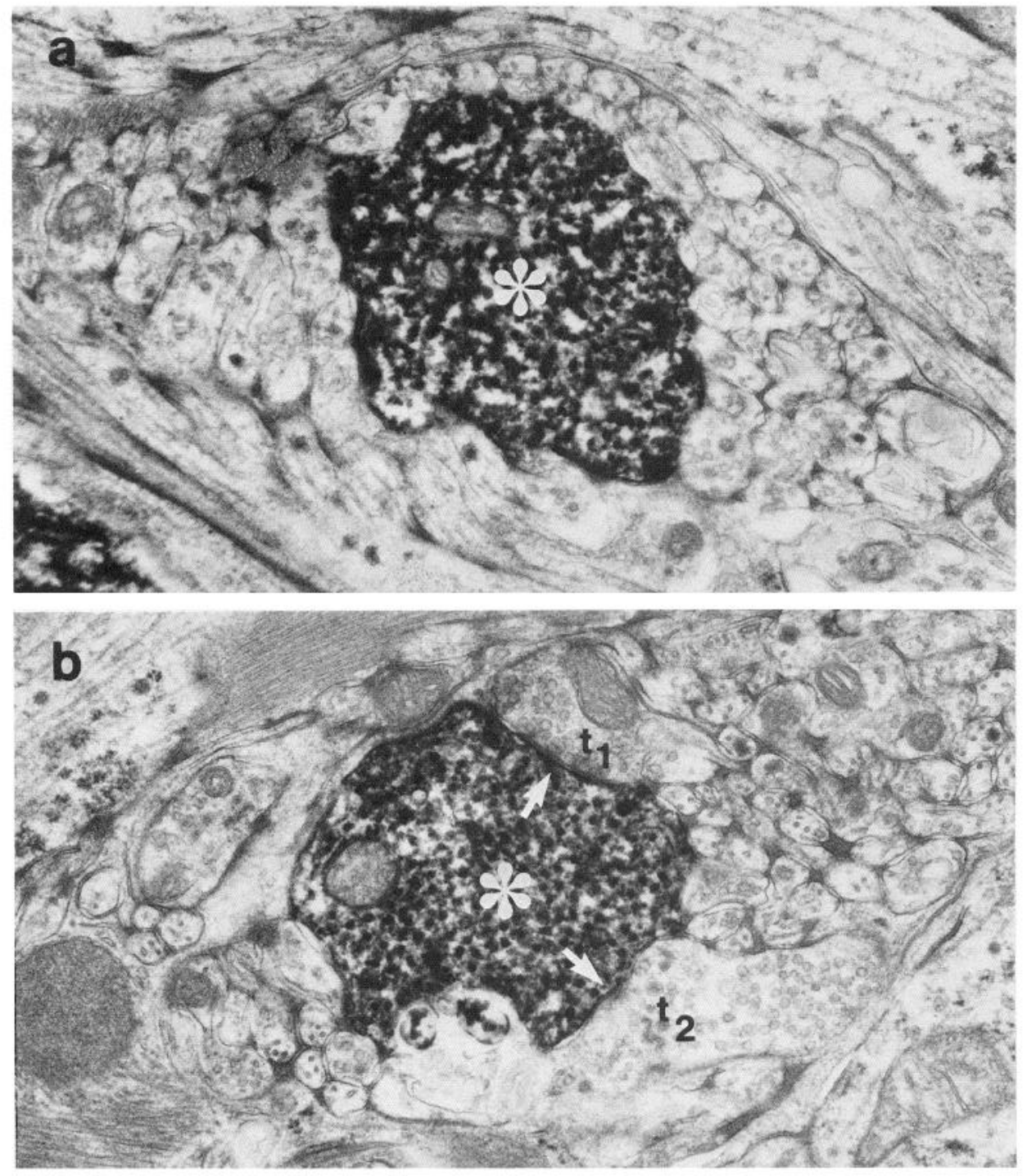

Figure 6. Series of electron micrographs showing a main dendritic shaft (asterisks) of a nocireceptive neuron (neuron $B$ in Fig. 1 and Table 1). $a$, the shaft is surrounded by a ring of fine fibers. $b$ and $c$, They enlarge occasionally and synapse with the shaft $\left(t_{1}\right.$ and $t_{3}$ and possibly $t_{2}$ and $t_{4}$ ) and with protrusions $\left(t_{5}\right)$; arrows point to the synaptic specializations. Scale bar, $1 \mu \mathrm{m}$.

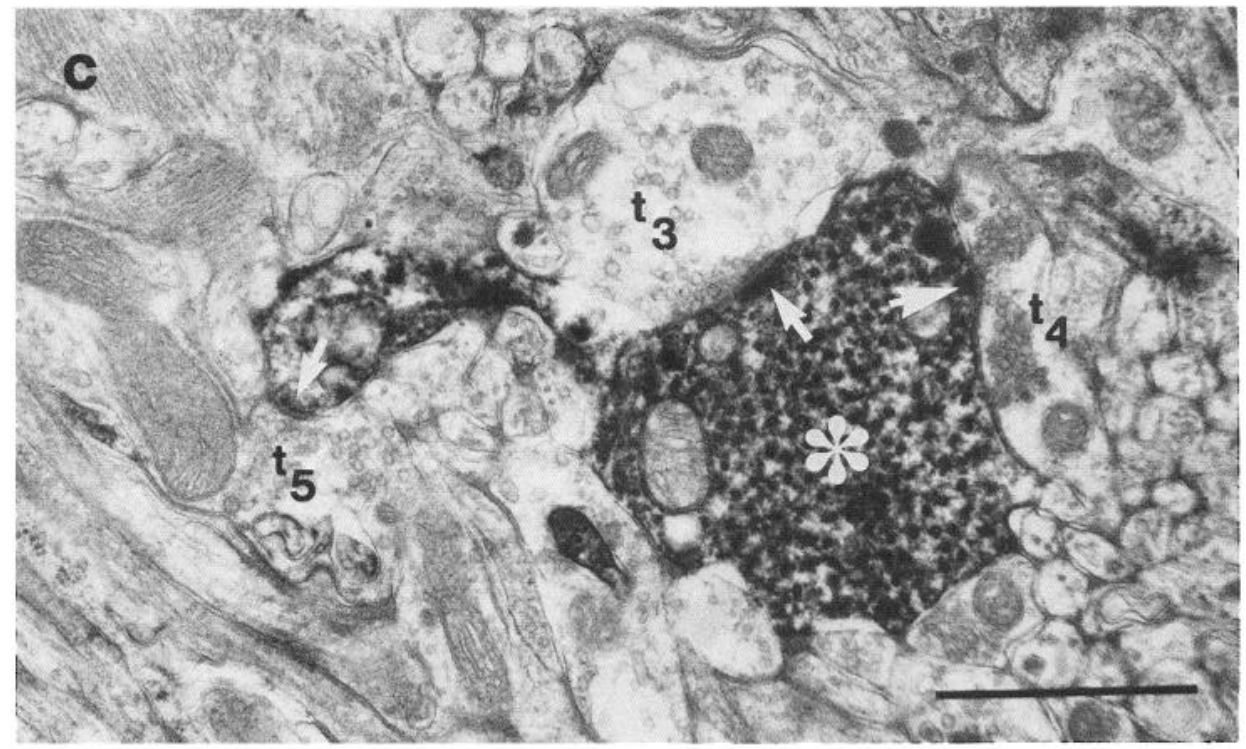



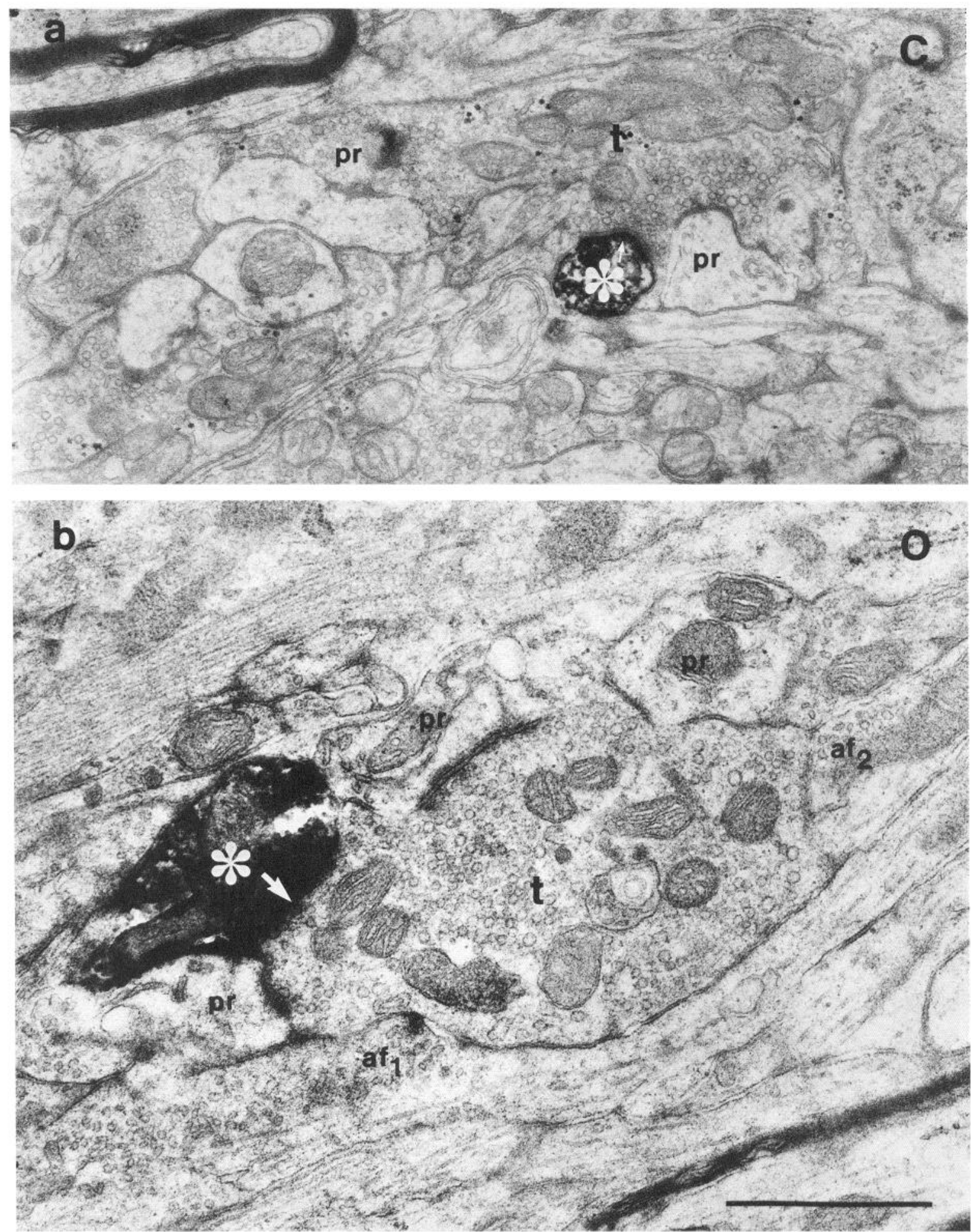

Figure 7. Electron micrographs showing glomerular synaptic contacts between large-size axon terminals $(t)$ containing spherical synaptic vesicles and protrusions of labeled (asterisks) and unlabeled neurons ( $p r$ ); arrows point to the synaptic specializations. The upper case letter in each panel's upper-right corner indicates the code of the neuron (see Fig. 1 and Tables 1 and 2). $a$, Glomerular synapse in lamina I resembling those described as the central terminals of myelinated mechanical nocireceptors (Rèthelyi et al., 1982); $b$, glomerular synapse in lamina $\mathrm{II}_{\mathrm{i}}$ resembling $\mathrm{C}_{\text {-type }}$ terminals, axons with flattened synaptic vesicles $\left(a f_{1}\right.$ and $\left.a f_{2}\right)$ form axonaxonic synapses with the large terminal, the synaptic specializations are visible on adjacent serial sections. Scale bar, $1 \mu \mathrm{m}$. 

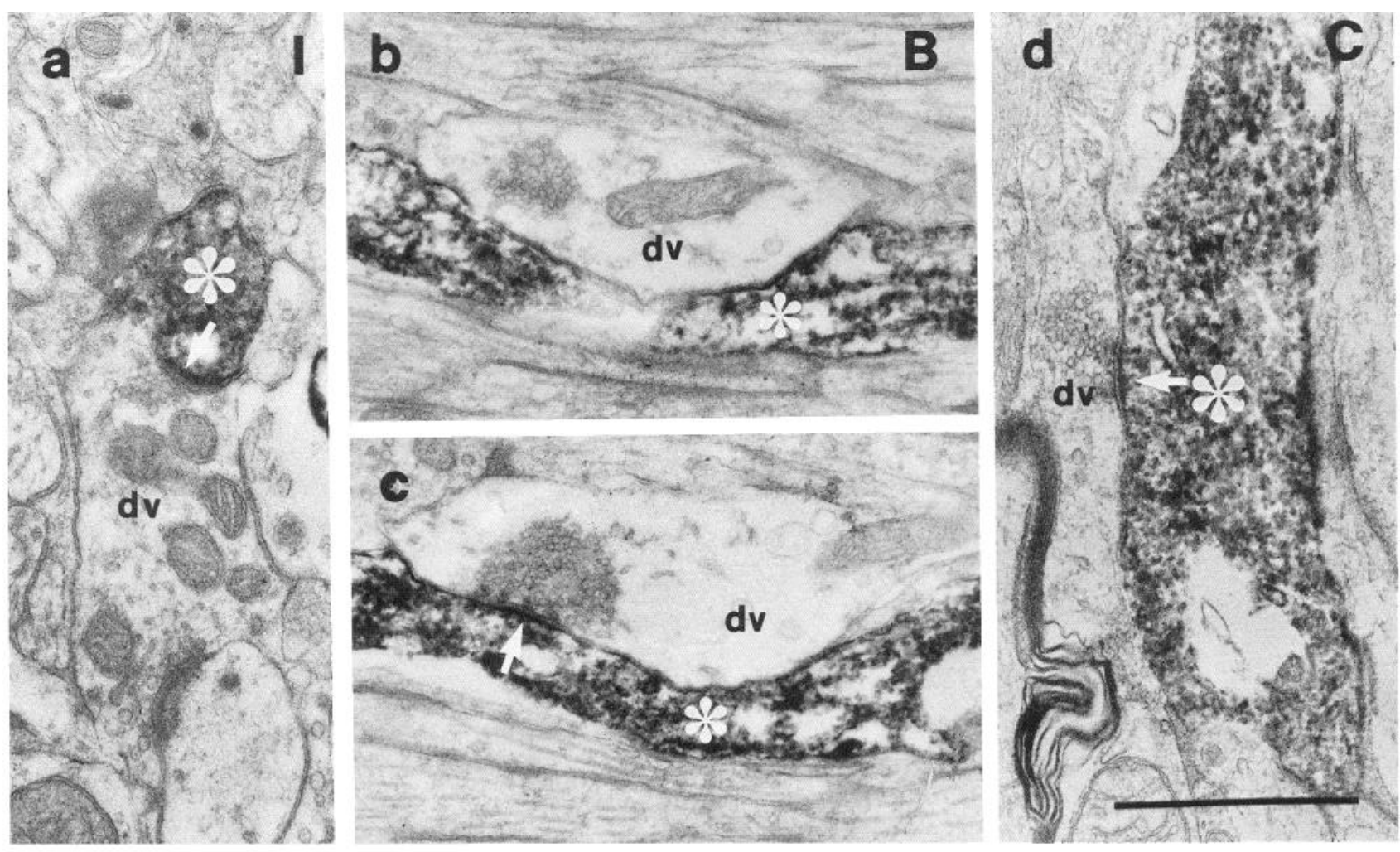

Figure 8. Electron micrographs showing dendrodenritic synaptic contacts between unlabeled vesicle containing dendrites $(d v)$ and dendrites of labeled neurons (asterisks); arrows point to the synaptic specializations. The upper case letter in each panel's upper-right corner indicates the code of the neuron (see Fig. 1 and Table 1). $a$, The vesicle containing dendrite synapses with 2 dendrites, one of them belonging to the labeled nocireceptive neuron $\left(^{*}\right) ; b$ and $c$, adjacent regions of a dendrodendritic synapse; $d$, the dendrodendritic synapse is between 2 dendrites positioned parallel. Scale bar, $1 \mu \mathrm{m}$.

unknown origin surrounded by relatively few postsynaptic elements (e.g., Figs. $7 b$ and $9 a-d$ ).

Detailed study of both multireceptive neurons did not uncover synaptic contact from glomerular arrangements along their extensive dendritic arborizations in lamina $\mathrm{I}$ and $\mathrm{II}_{\mathrm{o}}$. Exhaustive search of multiple sets of serial sections of the other 9 selectively responsive neurons also failed to uncover glomerular synaptic connections.

Three selectively nocireceptive neurons $(B, C, I)$, received synaptic contacts from presumed dendritic profiles. These presynaptic dendritic profiles contained small clusters of pleomorphic synaptic vesicles observed only in a limited number of serial sections. The presynaptic dendritic profiles were otherwise indistinguishable from the more usual vesicle-free dendrites (Fig. $8, a-d)$.

\section{Synaptic domains}

With the exception of the dendrodendritic connections to the nocireceptive neurons, none of the synaptic arrangements appeared unique to a functional class or subclass of neurons. On the other hand, while there was no specialization of synapses evident to the functional category of excitatory input, a form of synaptic specialization was found to exist for each neuron, as an individual element, within a certain domain of its dendritic extensions. The latter phenomena became evident as labeled profiles were followed in serial sections. If a neuron received a contact as part of a complex synapse, it received a series of similar contacts from such complexes for a considerable stretch of a dendrite's extension. Furthermore, other dendritic branches of the same neuron at the same spinal gray laminar level also participated in similar synaptic arrangements. Examples of multiple complex synapses for dendrites of a mechanoreceptive neuron in the lamina $\mathrm{II}_{\mathrm{i}}-\mathrm{III}$ border appear in Figure 9, $a-d$. In contrast with this repeated glomerular synaptic arrangement of one neuron, other labeled cells with dendrites passing through identical laminae were the recipients of only simple synaptic contacts.

\section{Efferent synapses of labeled neurons}

Axons of the labeled neurons arborized and established axodendritic synapses. En passant axon contacts of specific nocireceptive and mechanoreceptive neurons were similar in their ultrastructure (Fig. 10, $a-g$ ). Figure 10 illustrates a feature common to en passant axonic synapses of the labeled cells; a tendency for the presynaptic swelling to partially encircle the postsynaptic dendritic profile was commonly noted. Axonic enlargements of the labeled neurons were small $(0.5-1.0 \mu \mathrm{m})$ and contained a variety of clear, round or partially compressed vesicles. They typically also included several dense-core vesicles. In our sample, axons of the labeled neurons formed simple, symmetric synapses with dendrites; however, other neurons located in the same region but selected for their deep penetrating axons have been found to have axons making asymmetrical simple synapses (Light and Kavookjian, 1988).

Two of the selectively mechanoreceptive neurons located at the junction of laminae II and III (Fig. $1, J, O$ ) contained small 

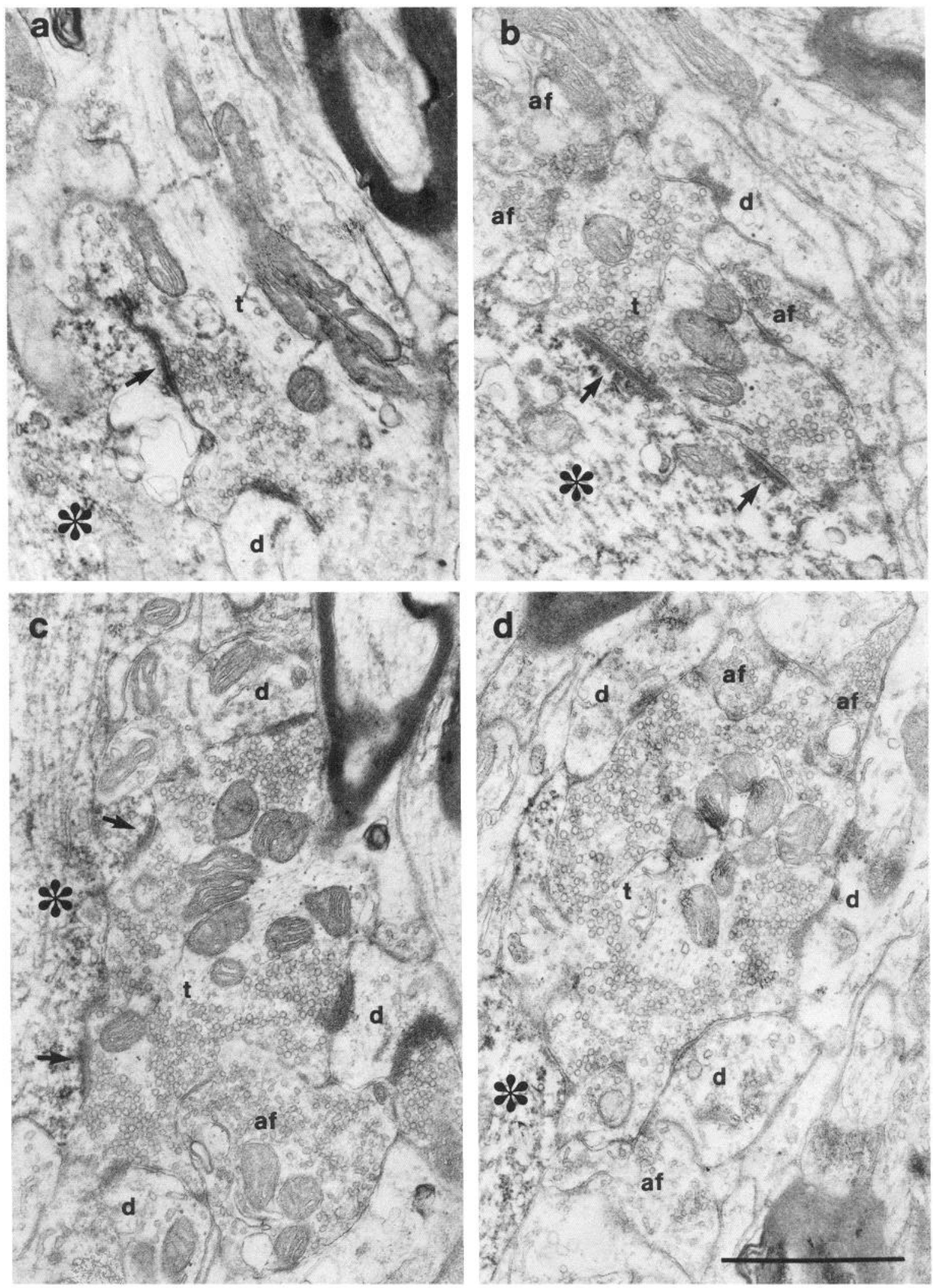

Figure 9. Electron micrographs showing glomerular synaptic contacts between large-size axon terminals $(t)$ containing spherical synaptic vesicles and various dendritic shaft regions (asterisks) of a mechanoreceptive neuron (neuron $K$ in Fig. 1 and Table 2), as well as with unlabeled dendrites (d); arrows point to the synaptic specializations between the large terminals and the labeled dendrites. Characteristically in such C-type glomerular synapses, the axon terminal in the center of the glomerulus is contacted by several small, flattened vesicle containing axons ( $a f$ ). Scale bar, $1 \mu \mathrm{m}$. 

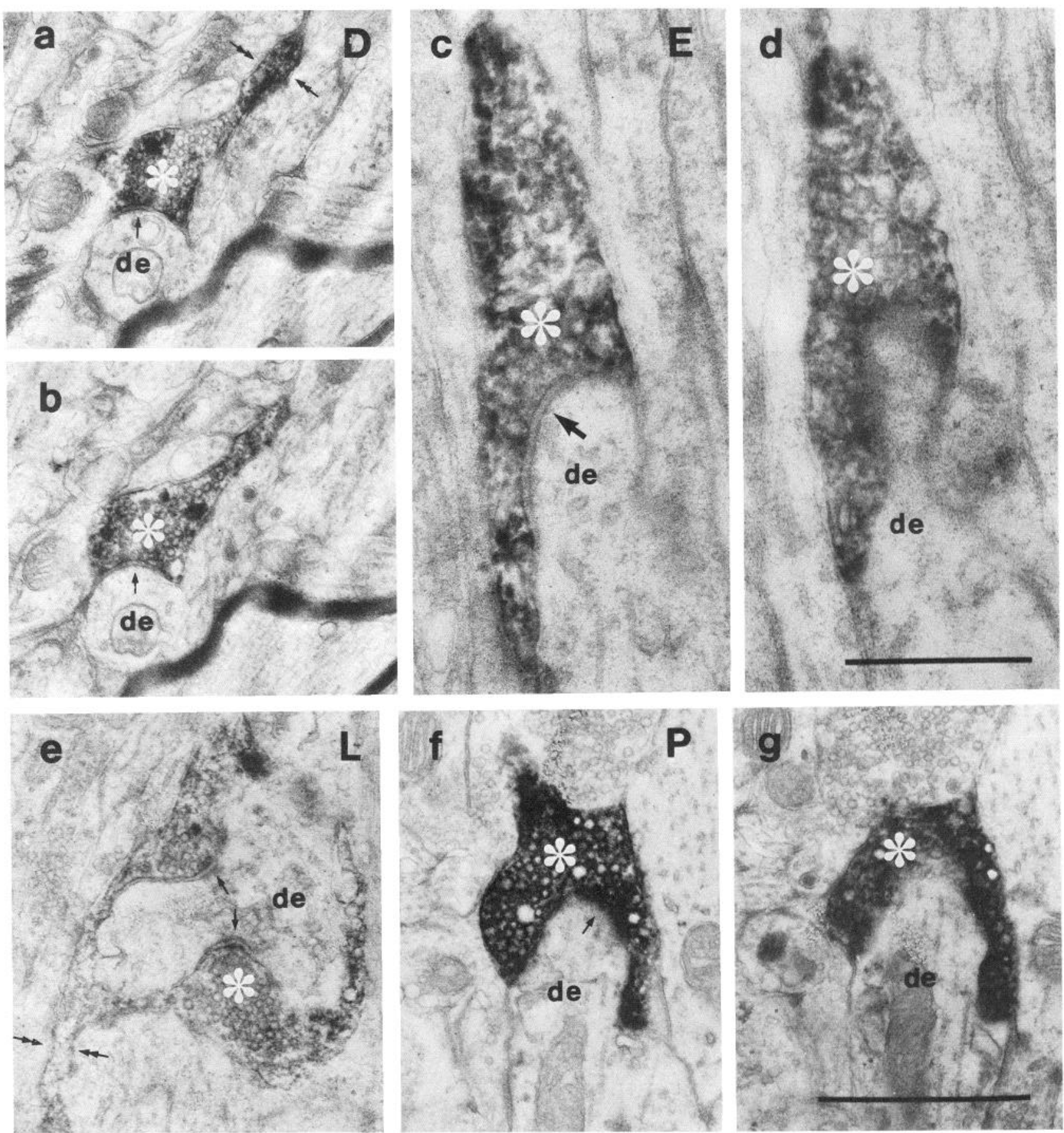

Figure 10. Single ( $e$ ) and serial electron micrographs ( $a$ and $b ; c$ and $d ; f$ and $g$ ) showing axodenritic synaptic contacts between the axon enlargements of labeled neurons (asterisks) and nonlabeled dendrites (de); arrows point to the synaptic specializations. The upper case letter in each panel's upper-right corner indicates the code of the neuron (see Fig. 1 and Tables 1 and 2). Enlargements are usually en passant boutons; the narrow interconnecting portions of the axon tree are well visible in $a$ and $e$ (between double arrows). Often the enlargements partially encircle the postsynaptic dendrites. Scale bars, $0.5 \mu \mathrm{m}$ for $c$ and $d$ and $1 \mu \mathrm{m}$ for other panels.

clusters of synaptic vesicles in their dendrites and were the presynaptic elements in dendrodendritic, symmetrical synapses with adjacent nonlabeled dendrites (Fig. 11, $a, b$ ). Vesicles were not noted in the dendritic extensions of the other 16 neurons.

\section{Discussion}

A particular functional class of primary afferent fiber (e.g., Group IA, G-hair, Type-I, myelinated fiber mechanical nocireceptor,
C-fiber nocireceptor) has been shown to have a unique termination pattern in the spinal dorsal horn (Light and Perl, 1979b; Brown, 1981; Sugiura et al., 1986). This close correlation between functional attributes and structural features, however, was not found in a past study of laminae I and II neurons (Light et al., 1979). We also were unable to demonstrate such structurefunction relationships in our present analyses of the 18 superficial dorsal horn neurons. Neurons with a particular type of excitatory input varied widely in the geometric arrangement of 

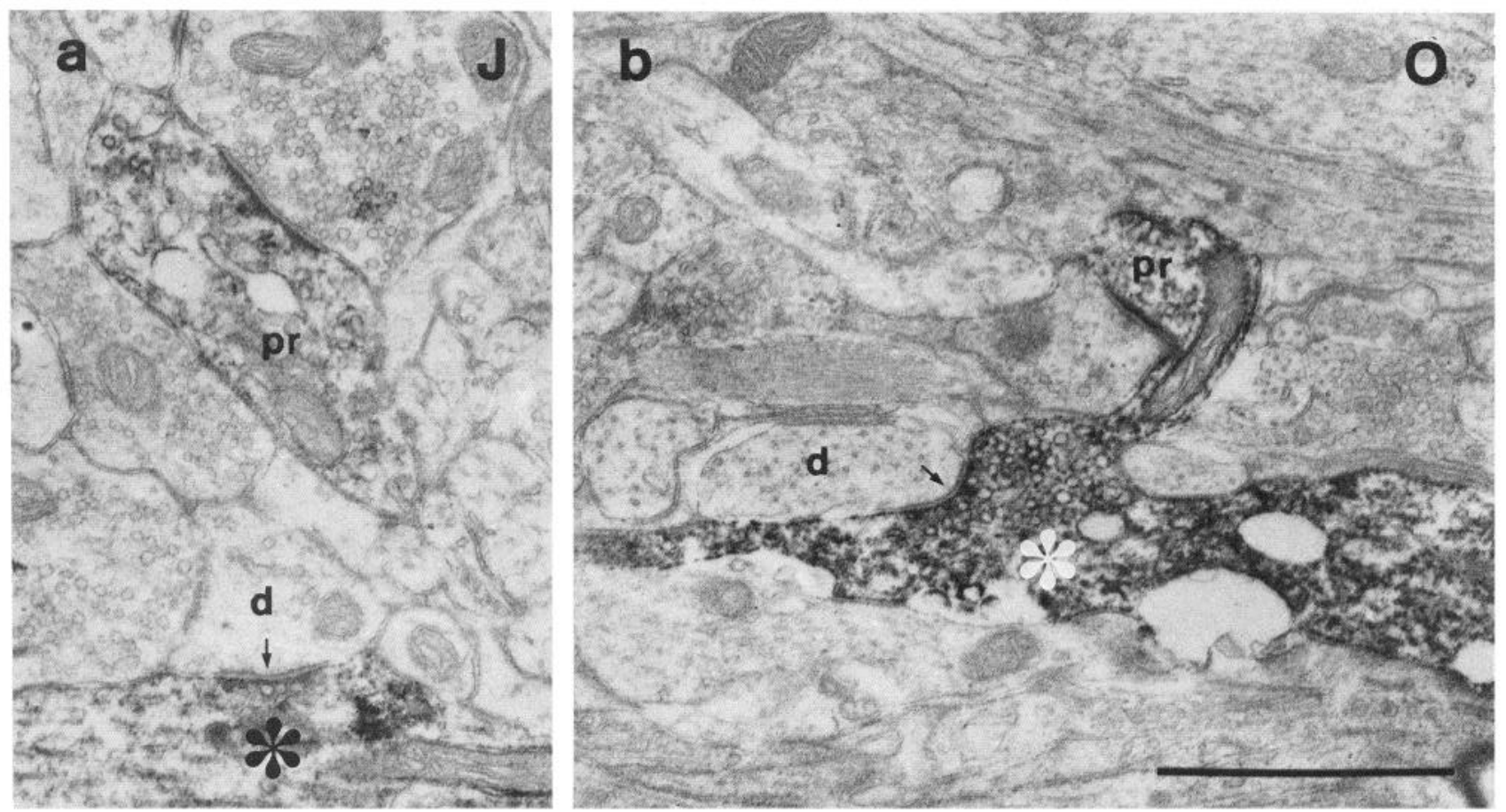

Figure 11. Electron micrographs showing synaptic contacts between dendrites of labeled neurons containing spherical synaptic vesicles (asterisks) and unlabeled dendrites $(d)$; arrows point to the synaptic specializations. The upper case letter in each panel's upper-right corner indicates the code of the neuron (see Fig. 1 and Tables 1 and 2). In both cases, a dendritic protrusion (pr) originates from the shaft next to the clusters of synaptic vesicles. Scale bar, $1 \mu \mathrm{m}$.

their dendritic trees. In other words, limitrophe (stalked) or central (islet) types of cells were found to be associated with more than one kind of functional category in terms of the major or dominant kind of excitatory input from the periphery. On the other hand, the reflection of the dominant types of primary afferent excitation by the lamina location of the major dendritic arborization noted previously (Light et al., 1979) was confirmed. Thus, nocireceptive neurons have their dendritic spreads predominantly in laminae $\mathrm{I}$ and $\mathrm{II}_{\mathrm{o}}$, while innocuous mechanoreceptive neuurons showed predominant dendritic arborizations in laminae $\mathrm{II}_{\mathrm{i}}$ and III.

A close relationship between ultrastructure and function does not appear in our sample. Neurons of a particular functional class were not found to have specific types of synaptic arrangements. For example, all 9 nocireceptive neurons had functional evidence of excitation from myelinated nociceptors (HTM), and yet only 2 had dendrites that were involved in synaptic glomeruli in which the central bouton resembled that of the HTM (Rèthelyi et al., 1982). One had dendrites contacted in a glomerular arrangement by a "C-type" bouton (Maxwell and Rèthelyi, 1987), and all 9 received contacts from "simple" synapses. These "simple" synaptic boutons may originate from other superficial dorsal horn neurons (see below) or may be supraspinal in origin.

Similarly, of the 7 innocuous mechanoreceptive neurons that appeared to receive excitatory input from $\mathrm{A} \delta$ mechanoreceptors, only 2 received synapses that were similar to those described by Rèthelyi et al. (1982) as stemming from myelinated lowthreshold mechanoreceptors. Our observations do, however, argue for selective connections between axons and dendritic arborizations; individual neurons did not participate in all of the varieties of synaptic arrangements existing in the vicinity of their dendritic arborizations. For example, nocireceptive neu- rons never had dendrites that were contacted by central boutons of the "D-hair" type. Conversely, innocuous mechanoreceptive neurons never received contacts from "HTM-like" boutons even when their dendrites passed through laminae I or $\mathrm{II}_{\mathrm{o}}$. Dendrites of a particular neuron apparently maintain a "microdomain" (Lichtman et al., 1984) by repeatedly receiving synapses in a particular arrangement. Thus, the specificity of excitatory projections found in functional studies on the superficial dorsal horn may have a basis in a morphological selectivity of connections from primary afferent fibers. This type of selectivity in the superficial dorsal horn of cat is therefore similar to that shown to exist by Lichtman et al. (1984) for motoneurons of the bullfrog.

Our observations suggest that in the superficial dorsal horn (possibly in the entire dorsal horn, as well), 2 organizational principles determine the synaptic connections between primary sensory neurons and second-order spinal cord neurons (Rèthelyi, 1983). One is a geometrical principle, i.e., the distribution pattern of pre- and postsynaptic components. The laminar distribution of primary afferent fibers and dendritic arborizations confined to particular laminae may produce numerous modality-specific second-order neurons (Perl, 1984). On the other hand, convergence of impulses from noci- and low-threshold mechanoreceptors observed on certain units recorded in laminae I or $\mathrm{II}_{\mathrm{o}}$ (Price et al., 1979; Bennett et al., 1981) may be the result of some dendrites branching in lamina $\mathrm{I}$ and $\mathrm{II}_{\mathrm{o}}$, while others of the same neuron descend ventrally towards laminae $\mathrm{II}_{\mathrm{i}}$ and III. The other factor that determines the connections between primary and secondary neurons may be called the synaptic selectivity principle. Synaptic contacts are made only between specific presynaptic and postsynaptic elements in a particular locality. Synaptic selectivity is likely to act in concert with the 
geometrical principle. Thus, rather specific types of contact are repeatedly found along an individual dendrite.

In contrast to the diversity in afferent synapses, nocireceptive and mechanoreceptive neurons were remarkably uniform in the ultrastructure of en passant enlargements from their axon arborization. Moreover, none of the observed axonic swellings formed recognizable axoaxonic connections. Therefore, the types of dorsal horn neurons we studied do not appear to contribute to the presynaptic axonic profiles reported for this part of the spinal cord dorsal horn. It is interesting to compare the structural differences of primary afferent terminals in the superficial dorsal horn to the uniformity of axon terminals of the neurons of the region. Synaptic enlargements of primary sensory neurons are mostly large boutons, synapse with several dendrites, and receive presynaptic connections (cf., Maxwell and Rèthelyi, 1987). Axon terminals of second-order neurons are small, synapse exclusively with one postsynaptic profile, and do not receive presynaptic connections.

Finally, vesicle-containing dendrites that are presynaptic to other dendrites may be a feature of some elements of a functional subtype, the low-threshold mechanoreceptive neurons of lamina II-III region. This correlation confirms earlier reports (Bennett et al., 1980; Gobel et al., 1980).

In conclusion, the same approach that made it possible to correlate function and structure for fine myelinated primary afferent fibers (Rèthelyi et al., 1982) has led to a different conclusion about neurons of the superficial dorsal horn excited by these afferent fibers. Functionally similar neurons of laminae I and II in terms of peripheral excitation do vary in their general geometry and synaptic arrangments.

\section{References}

Beal, J. A., and M. H. Cooper (1978) The neurons in the gelatinosal complex (laminae II and III) of the monkey (Macaca mulatta): A Golgi study. J. Comp. Neurol. 179: 89-121.

Bcal, J. A., and C. A. Fox (1976) Afferent fibers in the substantia gelatinosa of the adult monkey (Macaca mulatta): A Golgi study. J. Comp. Neurol. 168: 113-144.

Beal, J. A., J. E. Penny, and H. R. Bicknell (1981) Structural diversity of marginal (lamina I) neurons in the adult monkey (Macaca mulatta) lumbosacral spinal cord: A Golgi study. J. Comp. Neurol. 202: $237-$ 254.

Bennett, G. J., H. Hayashi, M. Abdelmoumene, and R. Dubner (1979) Physiological properties of stalked cells of the substantia gelatinosa intracellularly stained with horseradish peroxidase. Brain Res. 164 . 285-289.

Bennett, G. J., M. H. Abdelmoumene, H. Hayashi, and R. Dubner (1980) Physiology and morphology of substantia gelatinosa neurons intracellularly stained with horseradish peroxidase. J. Comp. Neurol. 194: 809-827.

Bennett, G. J., M. Abdelmoumene, H. Hayashi, M. J. Hoffert, and R. Dubner (1981) Spinal cord layer I neurons with axon collaterals that generate local arbors. Brain Res. 209: 421-426.

Brown, A. G. (1981) Organization in the Spinal Cord, Springer-Verlag, Berlin.

Brown, A. G., and M. Rèthelyi (1981) In Spinal Cord Sensation: Sensory Processing in the Dorsal Horn, Scottish, Edinburgh.

Christensen, B. N., and E. R. Perl (1970) Spinal neurons specifically excited by noxious or thermal stimuli: Marginal zone of the dorsal horn. J. Neurophysiol. 33: 293-307.

Coimbra, A., B. P. Sodre-Borges, and M. M. Magalhaes (1974) The substantia gelatinosa Rolandi of the rat. Fine structure, cytochemistry (acid phosphatase) and changes after dorsal root section. J. Neurocytol. 3: 199-217.

Conradi, S., J. O. Kellerth, and C. H. Berthold (1979) Electron microscopic studies of serially sectioned cat spinal $\alpha$-motorneurons. J. Comp. Neurol. 184: 741-753.

Dostrovsky, J. O., and R. F. Hellon (1978) The representation of facial temperature in the caudal trigeminal nucleus of the cat. J. Physiol (Lond.) 277: 29-47.

Foerster, O., and O. Gagel (1932) Die Vorderseitenstrangdurchschneidung beim Menschen. Eine klinisch.patho.physiologisch.anatomische Stud. Z. Ges. Neurol. Psychiatr. 138: 1-92.

Gobel, S., W. M. Falls, G. J. Bennett, M. Abdelmoumene, H. Hayashi, and E. Humphrey (1980) An EM analysis of the synaptic connections of horseradish peroxidase filled stalked cells and islet cells in the substantia gelatinosa of adult cat spinal cord. J. Comp. Neurol. 194: 781-807.

Golgi, C. (1903) In Istologia normale. Opera Omnia. Hoepli, Milan.

Jochem, W. J., A. R. Light, and D. Smith (1981) A high voltage electrometer for recording and iontophoresis with fine-tipped, high resistance microelectrodes. J. Neurosci. Methods 3: 261-269.

Kerr, F. W. L. (1966) The ultrastructure of the spinal tract of the trigeminal nerve and the substantia gelatinosa. Exp. Neurol. 16: 359376.

Kerr, F. W. L. (1970) The organization of primary afferents in the subnucleus caudalis of the trigeminal: A light and electron microscopic study of degeneration. Brain Res. 23:147-165.

Knyihar, E., I. Laszlo, and S. Tornyos (1974) Fine structure and fluoride resistant acid phosphatase activity of electron dense sinusoid terminals in the substantia gelatinosa Rolandi of the rat after dorsal root transection. Exp. Brain Res. 19: 529-544.

Kumazawa, T., and E. R. Perl (1976) Differential excitation of dorsal horn marginal and substantia gelatinosa neurons by primary afferent units with fine (A $\alpha$ and C) fibers. In Sensory Functions of the Skin in Primates, Y. Zotterman, ed., pp. 67-88, Pergamon, New York.

Kumazawa, T., and E. R. Perl (1978) Excitation of marginal and substantia gelatinosa neurons in the primate spinal cord: Indications of their place in dorsal horn functional organization. J. Comp. Neurol. 177: 417-434.

Kuru, M. (1949) Sensory Paths in the Spinal Cord and Brain Stem of Man, pp. 657-713, Sogensya, Tokyo.

Lenhossek, M. v. (1895) Der feinere Bau des Nervensystems in Lichte neuester Forschungen. Eine allgemeine Betrachtung der Strukturprinzipien des Nervensystems, nebst einer Darstellung des feineren Baues des Rückenmarkes, pp. 1754-1768, Kornfeld, Berlin.

Lichtman. J. W., S. Jhaveri, and E. Frank (1984) Anatomical basis of specific connections between sensory axons and motor neurons in the brachial spinal cord of the bullfrog. J. Neurosci. 4: 1754-1763.

Light, A. R., and A. M. Kavookjian (1988) Morphology and ultrastructure of physiologically identified substantia gelatinosa (lamina II) neurons with axons that terminate in deeper dorsal horn laminae (III-V). J. Comp. Neurol. 267: 172-189.

Light, A. R., and E. R. Perl (1979a) Reexamination of the dorsal root projection to the spinal dorsal horn including observations on the differential termination of coarse and fine fibers. J. Comp. Neurol. 186: 117-131.

Light, A. R., and E. R. Perl (1979b) Spinal termination of functionally identified primary afferent neurons with slowly conducting myelinated fibers. J. Comp. Neurol. 186: 133-150.

Light, A. R., D. L. Trevino, and E. R. Perl (1979) Morphological features of functionally defined neurons in the marginal zone and substantia gelatinosa of the spinal dorsal horn. J. Comp. Neurol. 186: 151-171.

Mannen, H., and Y. Sugiura (1976) Reconstruction of neurons of dorsal horn proper using golgi-stained serial sections. J. Comp. Neurol. 168: 303-312.

Matsushita, M. (1969) Some aspects of the interneuronal connections in cat's spinal gray matter. J. Comp. Neurol. 136: 57-80.

Maxwell, D. J., and M. Rethelyi (1987) Ultrastructure and synaptic connections of cutaneous afferent fibres in the spinal cord. TINS 10: 117-123.

Metz, C. B., A. M. Kavookjian, and A. R. Light (1982) Techniques for HRP intracellular staining of neural elements for light and electron microscopic analyses. J. Electrophysiol. Tech. 9: 151-163.

Molony, V., W. M. Steedman, F. Cervero, and A. Iggo (1981) Intracellular marking of identified neurones in the superficial dorsal horn of the cat spinal cord. Q. J. Exp. Physiol. 66: 211-223.

Narotzky, R. A., and F. W. L. Kerr (1978) Marginal neurons of the spinal cord: Types, afferent synaptology and functional considerations. Brain Res. 139: 1-20.

Pearson, A. A. (1952) Role of gelatinous substance of spinal cord in conduction of pain. Arch. Neurol. Psychiatr. 68: 515-529. 
Perl, E. R. (1984) Pain and nociception. In Handbook of Physiology. The Nervous System, Vol. 3, I. Darian-Smith, ed., pp. 915-975, American Physiological Society, Bethesda, MD.

Price, D. D., H. Hayashi, R. Dubncr, and M. A. Ruda (1979) Functional relationships between neurons of marginal and substantia gelatinosa layers of primate dorsal horn. J. Neurophysiol. 42: 15901608.

Ralston, H. J. III (1968a) The fine structure of neurons in the dorsal horn of the cat spinal cord. J. Comp. Neurol. 132: 275-302.

Ralston, H. J. III (1968b) Dorsal root projections to dorsal horn of the cat spinal cord. J. Comp. Neurol. 132: 303-329.

Ralston, H. J. III (1979) The fine structure of laminae I, II and III of the Macaque spinal cord. J. Comp. Neurol. 184: 619-641.

Ramón y Cajal, S. (1909) Histologie du Système Nerveux de l'Homme et des Vertébrés, Vol. 1, Maloine, Paris.

Ranson, S. W. (1915) Unmyelinated nerve fibres as conductors of protopathic sensation. Brain 38: 381-389.

Rèthelyi, M. (1983) Specificity versus convergence of nociccptivc and mechanoreceptive impulses in the spinal dorsal horn. Fortschr. Zool. Bd. 28, E. Horn, ed., pp. 33-46, Gustav Fischer Verlag, Stuttgart.

Rèthelyi, M., and J. Szentàgothai (1969) The large synaptic complexes of the substantia gelatinosa. Exp. Brain Res. 7: 258-274.

Rèthelyi, M., and J. Szentàgothai (1973) Distribution and connections of afferent fibres in the spinal cord. In Handbook of Sensory Physiology, Vol. 2, Somatosensory System, A. Iggo, ed., pp. 207-252, Springer, Berlin.

Rèthelyi, M., D. L. Trevino, and E. R. Perl (1979) Distribution of primary afferent fibers within the sacrococcygeal dorsal horn: An autoradiographic study. J. Comp. Neurol. 185: 603-621.
Rèthelyi, M., A. R. Light, and E. R. Perl (1982) Synaptic complexes formed by functionally defined primary afferent units with fine myelinated fibers. J. Comp. Neurol. 207: 381-393.

Rèthelyi, M., A. R. Light, and E. R. Perl (1983) Synapses made by nociceptive laminae I and II neurons. Adv. Pain Res. Ther. 5: 111117.

Rethelyi, M., A. R. Light, and E. R. Perl (1985) Synaptic contacts on physiologically defined neurons of the superficial dorsal horn. Adv. Pain Res. Ther. 9: 139-147.

Rexed, B. (1954) A cytoarchitectonic atlas of the spinal cord in the cat. J. Comp. Neurol. 100: 297-379.

Scheibel, M. E., and A. B. Scheibel (1968) Terminal axonal patterns in cat spinal cord. II. The dorsal horn. Brain Res. 9: 32-58.

Sindou, M., C. Quoex, and C. Baleydier (1974) Fiber organization at the posterior spinal cord-rootlet junction in man. J. Comp. Neurol. 153: 15-26.

Snyder, R. (1977) The organization of the dorsal root entry zone in cats and monkcys. J. Comp. Neurol. 174: 47-69.

Sugiura, Y. (1975) Three dimensional analysis of neurons in the substantia gelatinosa Rolandi. Proc. Jpn. Acad. 51: 336-341.

Sugiura, Y., C. L. Lee, and E. R. Perl (1986) Central projections of identified, unmyelinated $(\mathrm{C})$ afferent fibers innervating mammalian skin. Science 234: 358-361.

Szentàgothai, J. (1964) Neuronal and synaptic arrangement in the substantia gelatinosa Rolandi. J. Comp. Neurol. 122: 219-239.

Waldeyer, H. (1888) Das Gorilla-Ruckenmarck. Abhandlungen der Wissenschaften zu Berlin 3: 1-147. 